\title{
Implementation of Standardized Handoff Reporting to Improve Communication Among Certified Registered Nurse Anesthetists and Postanesthesia Care Unit Nurses in the Postanesthesia Care
} Unit

Lauryn G. MacFawn

West Virginia University, Igm0012@mix.wvu.edu

Follow this and additional works at: https://researchrepository.wvu.edu/etd

Part of the Perioperative, Operating Room and Surgical Nursing Commons

\author{
Recommended Citation \\ MacFawn, Lauryn G., "Implementation of Standardized Handoff Reporting to Improve Communication \\ Among Certified Registered Nurse Anesthetists and Postanesthesia Care Unit Nurses in the \\ Postanesthesia Care Unit" (2022). Graduate Theses, Dissertations, and Problem Reports. 10164. \\ https://researchrepository.wvu.edu/etd/10164
}

This Problem/Project Report is protected by copyright and/or related rights. It has been brought to you by the The Research Repository @WVU with permission from the rights-holder(s). You are free to use this Problem/Project Report in any way that is permitted by the copyright and related rights legislation that applies to your use. For other uses you must obtain permission from the rights-holder(s) directly, unless additional rights are indicated by a Creative Commons license in the record and/ or on the work itself. This Problem/Project Report has been accepted for inclusion in WVU Graduate Theses, Dissertations, and Problem Reports collection by an authorized administrator of The Research Repository @ WVU. For more information, please contact researchrepository@mail.wvu.edu. 
Implementation of Standardized Handoff Reporting to Improve Communication Among Certified Registered Nurse Anesthetists and Postanesthesia Care Unit Nurses in the Postanesthesia Care Unit

Lauryn G. MacFawn

Follow this and additional works at: https://researchrepository.wvu.edu/etd

Part of the Perioperative, Operating Room and Surgical Nursing Commons 
Implementation of Standardized Handoff Reporting to Improve Communication Among Certified Registered Nurse Anesthetists and Postanesthesia Care Unit Nurses in the Postanesthesia Care Unit

\title{
Lauryn Grace MacFawn, BSN, SRNA
}

Doctor of Nursing Practice Project submitted

to the School of Nursing

at West Virginia University

In partial fulfillment of the requirements for the degree of

Doctor of Nursing Practice in Nurse Anesthesia

\author{
Aaron Ostrowski, DNP, APRN, CRNA, Chair \\ William Lewis, APRN, CRNA \\ Department of Nursing
}

Morgantown, West Virginia

2021

Keywords: Standardized Handoff Reporting, Nurse Anesthetist, Postanesthesia Care Unit Copyright 2021 Lauryn MacFawn 


\author{
Abstract \\ Implementation of Standardized Handoff Reporting to Improve Communication Among \\ Certified Registered Nurse Anesthetists and Postanesthesia Care Unit Nurses in the \\ Postanesthesia Care Unit
}

\title{
Lauryn MacFawn
}

Standardization of handoff reporting has been proven to increase the quality of information being transferred and improve patient safety. Poor quality handoff between providers increases morbidity and mortality, hospital length of stay, healthcare costs, as well as decreases patient satisfaction The aim of this Doctor of Nursing Practice quality improvement (QI) project was to implement the situation, background, assessment, recommendation (SBAR) handoff reporting tool in the postanesthesia care unit (PACU) at a hospital in Western Maryland. There was no standardized handoff process in place between certified registered nurse anesthetists (CRNAs) and PACU registered nurses (RNs) at the facility. The participants in this project consisted of 17 CRNAs, 17 PACU RNs, and 3 nurse anesthetist students. The project took place over 13 weeks and involved a pre and post implementation survey, an education session with implementation of the SBAR handoff tool, handoff assessment forms, and a oneday adherence follow-up. Data was collected by the project designer using online and paper surveys and paper handoff assessment forms. All results remained anonymous. Statical analysis of the results revealed a statistically significant improvement $(P$ value $<0.05)$ in staff perception on patient handoff following implementation of the handoff tool in the areas of staff expectations, responsibility for safe patient care, and the opportunity to answer additional questions at the end of handoff report. The participants expressed their likes and dislikes on the current handoff process through open-ended questions in the pre/post-implementation surveys. Use of the SBAR handoff tool improved completeness in reporting of patient and procedure identification (87.6\% to $94.4 \%$ ), allergies (82.5\% to $83.3 \%$ ), intake and output (77.3\% to $94.4 \%$ ), airway assessment (50.5\% to $69.4 \%$ ), and lines and catheters (28.9\% to 66.7\%). The project designer concluded an overall improvement in provider perception on handoff reporting as well as improvement in completeness of report with the use of SBAR handoff reporting tool. Use of standardized handoff reporting is recommended to improve provider satisfaction and patient safety. 
Table of Contents

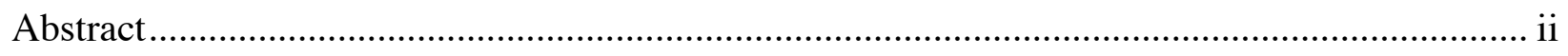

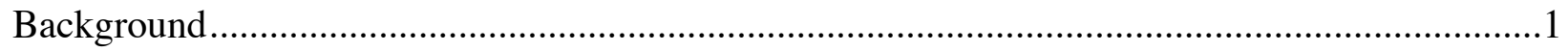

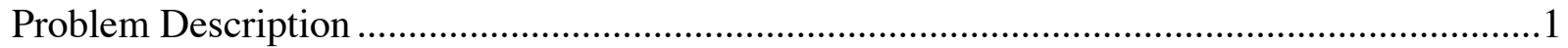

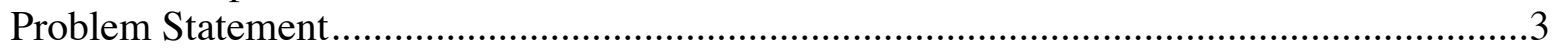

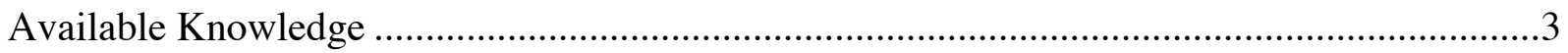

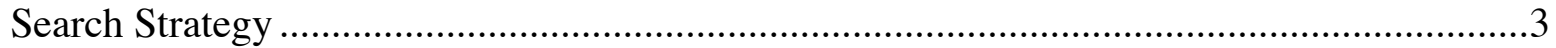

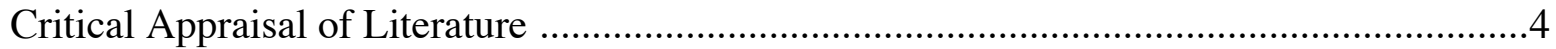

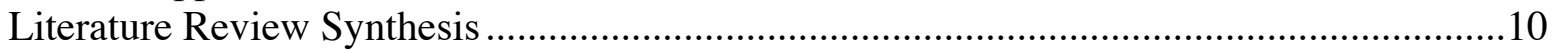

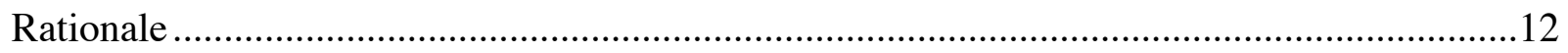

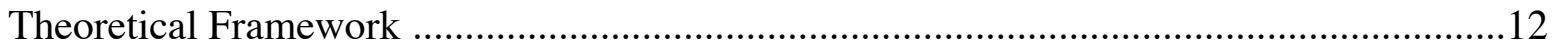

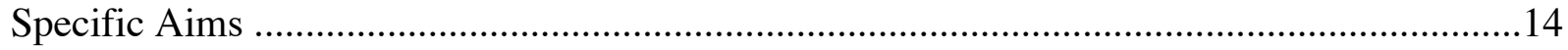

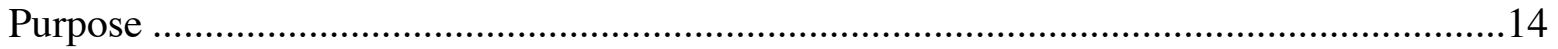

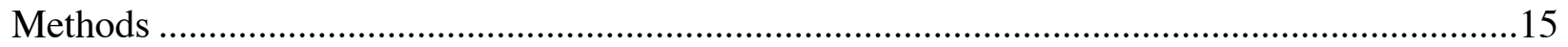

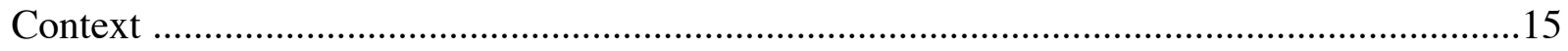

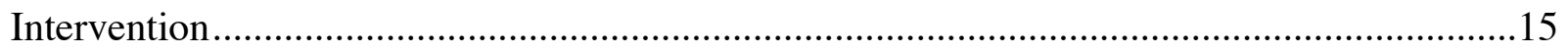

Alignment of the Intervention with Specific Aims ………............................................15

Gaps in Evidence .................................................................................................19

Congruence with the Organization's Strategic Plan ......................................................19

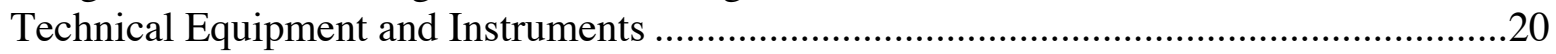

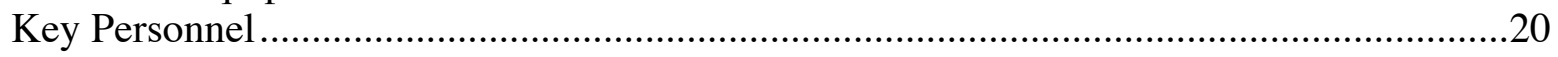

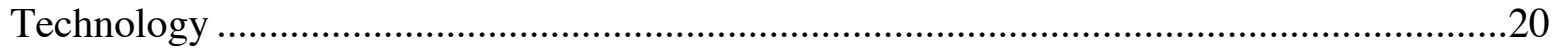

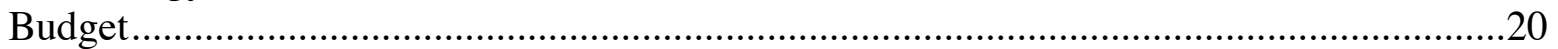

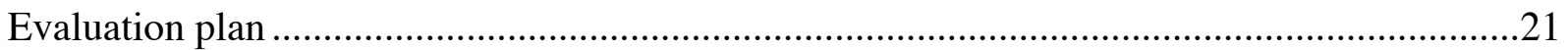

Assessing the Impact of the Intervention .....................................................................2.

Project Objectives: Correlation between Project Outcomes and Intervention ......................21

Strategies to Achieve the Specific Aims …………….........................................................22

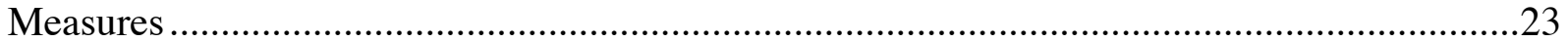

Measures for Studying Processes and Outcomes ……………......................................23

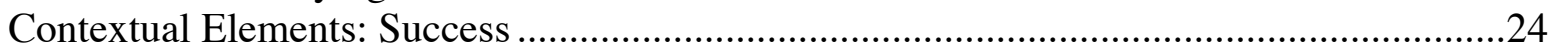

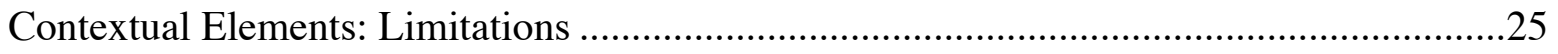

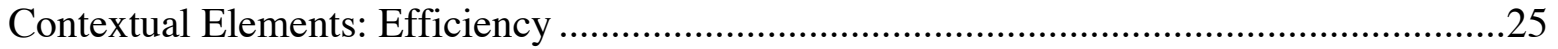

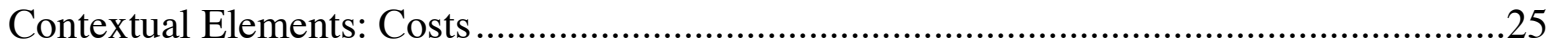

Methods to Assess Data Completeness and Accuracy ........................................................26

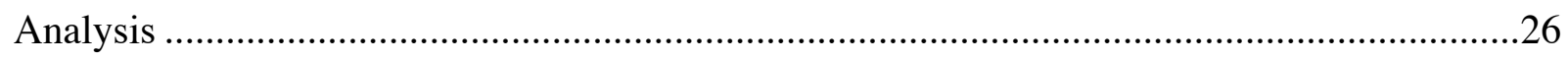

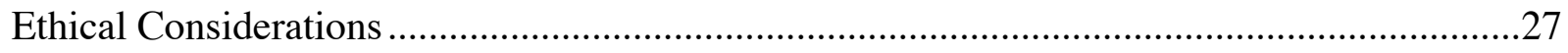

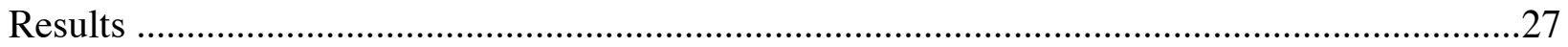

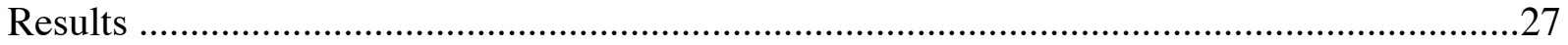

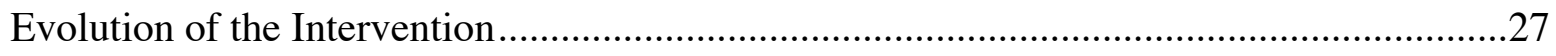


Process Measures and Outcome ...............................................................................28

Contextual Elements Associated with the Intervention ...................................................33

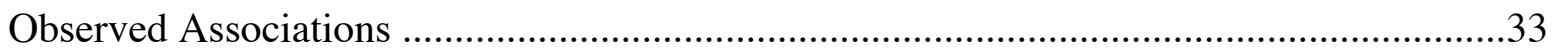

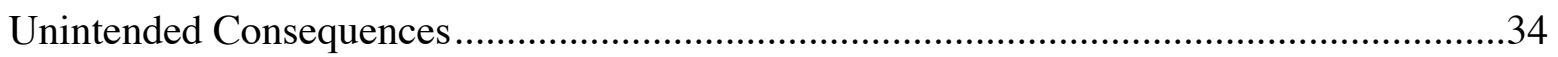

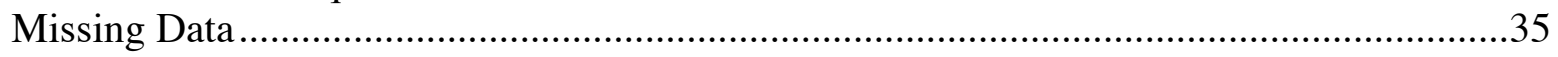

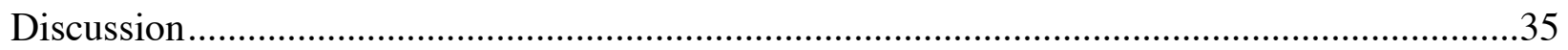

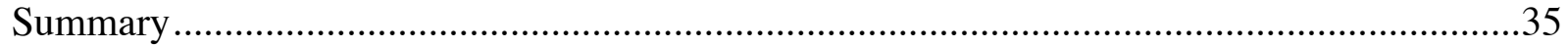

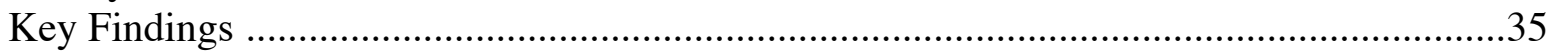

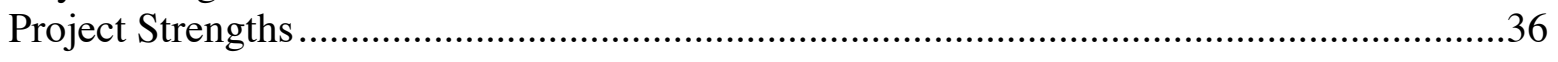

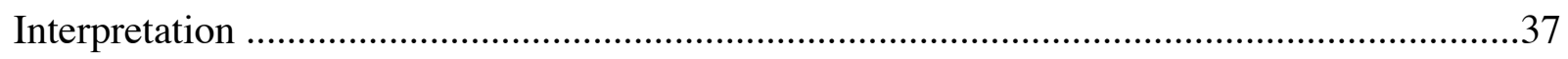

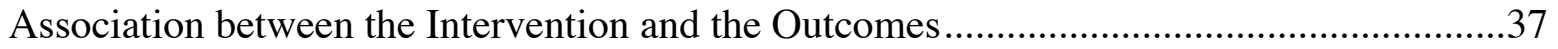

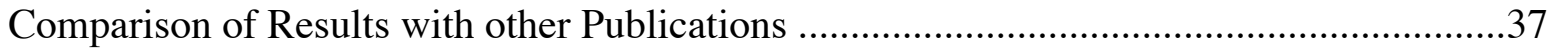

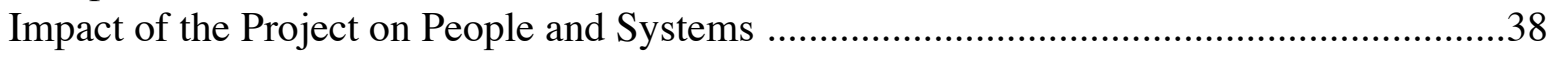

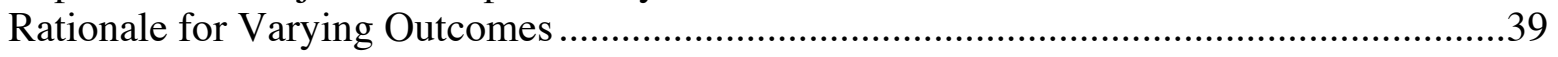

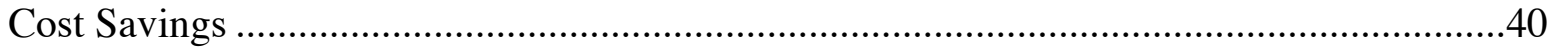

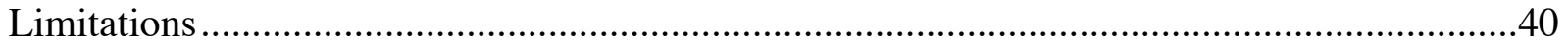

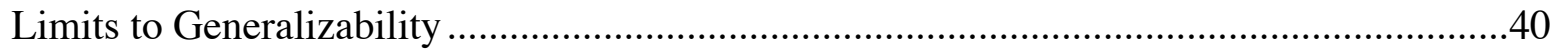

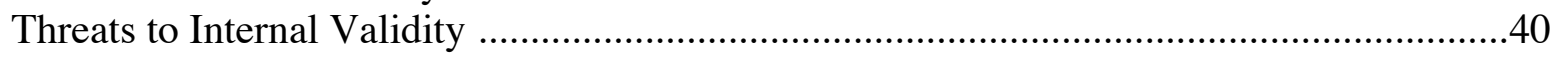

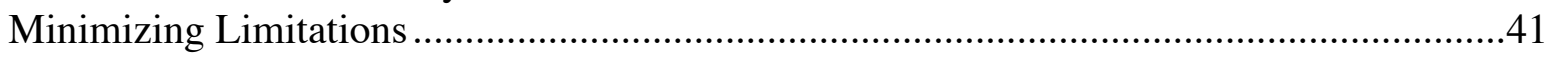

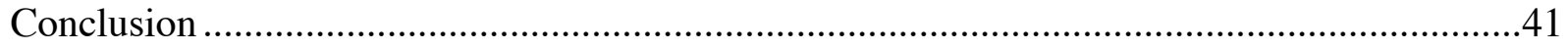

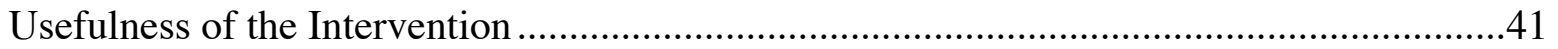

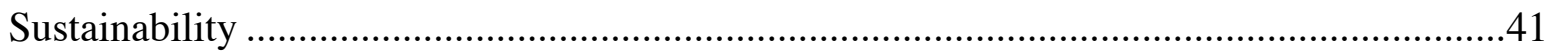

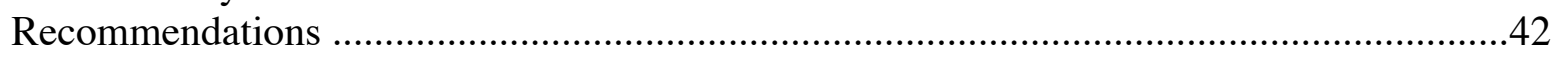

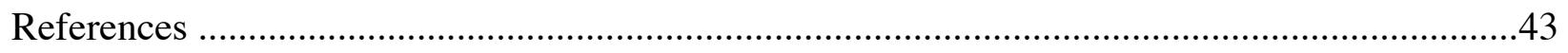




\section{Implementation of Standardized Handoff Reporting to Improve Communication Among}

Certified Registered Nurse Anesthetists and Postanesthesia Care Unit Nurses in the Postanesthesia Care Unit

Lack of standardization in handoff reporting poses a safety threat to patients. According to the Joint Commission, approximately $80 \%$ of medical errors result from miscommunication during patient handoff (The Joint Commission [TJC], 2012). One common area of occurrence is the postanesthesia care unit (PACU). Communication errors in the PACU can be attributed to high patient turnover, environmental distractions, and variability in handoff communication styles (Jones et al., 2018). Poor quality handoff between providers increases morbidity and mortality, hospital length of stay, healthcare costs, as well as decreases patient satisfaction (Rose, 2016). Implementing a standardized handoff tool during postoperative handover increases provider satisfaction and improves the quality of information being transferred (Rose et al., 2019). The focus of this project was to improve the transfer of patient information between certified registered nurse anesthetists (CRNA) and PACU registered nurses (RN) by implementing standardized handoff reporting in the PACU.

\section{Background}

\section{Problem Description}

This Doctor of Nursing Practice (DNP) project was implemented at a community hospital in Western Maryland. Standardized handoff reporting between CRNAs and PACU nurses has been shown to improve patient safety, but no such process was in place at this hospital. The perioperative RNs at this facility used a handoff form when giving report to the oncoming RN. Refer to appendix F for the OR communication tool in place at the facility. Informal consultation 
with the CRNAs and PACU nurses at this facility acknowledged variations in handoff reporting between the CRNAs.

Poor communication among healthcare providers creates a gap in patient care with the potential to cause serious harm (TJC, 2017). The American College of Surgeons claimed that $85 \%$ of adverse events result from a breakdown in verbal communication (Greenberg et al., 2007); this is due to loss of information and/or misunderstanding among providers (Robins \& Dai, 2015). Inadequate communication may occur in various departments in the healthcare system; however, it is common in the postoperative period (Rose, 2016). This problem can be attributed to lack of standardization in handoff reporting (Robins \& Dai, 2015).

In the postoperative period, patients are vulnerable and rely on healthcare providers to accurately communicate and advocate in their best interest (Rose, 2016). It is essential for anesthesia providers to relay pertinent information including past medical history, intraoperative events, and the postoperative plan during transfer of care to the PACU (Robins \& Dai, 2015). Various factors contribute to ineffective communication during this transition of care; these factors include distraction and interruption, time pressure, and lack of a standardized reporting framework (Leonardsen et al., 2019). Additionally, communication styles may vary among providers, potentially leading to unsatisfactory handoff (Robins \& Dai, 2015).

In 2016, medical errors were the $3^{\text {rd }}$ leading cause of death in the United States (Makary \& Daniel, 2016). In 2000, an estimated 98,000 deaths were due to medical errors every year (Institute of Medicine [IOM], 2000). An updated estimate of approximately 210,000-400,000 deaths each year are caused from medical errors (James, 2013). To improve patient safety, the Joint Commission recommends standardizing the handoff process (TJC, 2006). Standardized handoff reporting reduces loss of information during transition of care (Jullia et al., 2017). 
Patient outcomes in the postoperative period can be improved with consistent use of a standardized handoff tool.

\section{Problem Statement}

Lack of standardization in handoff reporting between CRNAs and PACU RNs has the potential to pose safety risks for patients in the postoperative period. Without a standardized handoff process in place, valuable information may be lost, ultimately threatening the safety and recovery of the patient.

\section{Available Knowledge}

A literature search was guided by the PICO question, "In the postanesthesia care unit, does implementing a standardized handoff tool between CRNAs and PACU nurses, compared to utilizing current handoff methods, improve communication and promote patient safety?" Handoff communication pertaining to anesthesia providers and PACU nurses in the postanesthesia care unit was reviewed. Relevant and generalizable studies were chosen to guide this quality improvement (QI) project.

\section{Search Strategy}

A comprehensive literature search was conducted using the following databases: Cumulative Index of Nursing and Allied Health Literature (CINAHL), PubMed, and Cochrane. These 3 databases yielded 188 results. Of these database searches, CINAHL yielded 118 results, PubMed yielded 66 results, and Cochrane yielded 4 results. Key words used for CINAHL database search included "anesthesia" or "anesthesiologist" or "anesthetist", "handoff" or "handover" or "hand off" or "hand-off" or "shift report", "PACU" or "post anesthesia" or "recovery" or "recovery room" or "recovery unit" or "post-surgery" or "after surgery". Key words used for PubMed database search included "anesthesia", "handoff", and 
"communication". Key words used for Cochrane database search included "anesthesia" and "handoff".

Articles published within the last five years and in the English language were used as limiters. These limiters yielded a total of 112 articles and 6 studies met the criteria that aligned with the project's PICO question. The six selected articles were QI observational studies.

\section{Critical Appraisal of Literature}

The six articles were appraised using Larrabee's critical appraisal tool for quantitative and mixed methods research. The following paragraphs will provide a comprehensive summary of each of the QI projects. Refer to Table 1 for the purpose, methodology, statistical analyses, results, strengths, and limitations of the studies.

A QI project by Robins and Dai (2015), was conducted to determine if utilizing a standardized handoff checklist in the PACU would improve the adequacy of handoff report between providers, increase clarification of information, and decrease the time spent in transfer of care. Prior to implementation of the standardized handoff tool into practice, a pilot study was conducted to assess validity and reliability of the handoff tool; the participants included 29 PACU RNs and 29 CRNAs. The participants reported the handoff tool was easy to use and the information was valid. The study assessed findings between two groups, each with 30 anesthesia providers. The study used a computer-generated randomized design to assign PACU RNs and CRNAs to one of two groups; both groups were blinded to the information in the checklist. Group 1 was instructed to use the standardized handoff tool, while group 2 continued with their typical reporting method. PACU RNs were educated on how to collect and record the data following handoff report from anesthesia providers. The following information was recorded after the handoff: information completeness, handoff adequacy, information clarification, and 
time. Statistical analysis was completed using the Fisher exact test and the Wilcoxon rank sum test. Results concluded $92 \%$ of PACU nurses were able to recall all information when the checklist was utilized during handoff. In comparison, only 54\% of PACU RNs were able to recall all information when the checklist was not utilized during handoff. A $P$ value of 0.0042 revealed that a statistically significant relationship existed between the use of a checklist and the number of PACU callbacks to anesthesia providers.

The study by Leonardsen et al. (2019) examined the impact of implementing the identification- situation- background- assessment- recommendation (ISBAR) tool for anesthesia handoff in the PACU at a hospital in Southeast Norway. The purpose of this cross-sectional quantitative QI project was to investigate staff perception and experience with utilization of a standardized handoff process between anesthesia providers and PACU nurses. The project included a pre and post implementation design to determine the effectiveness of the intervention. Prior to implementation, the handoff tool was evaluated by five nurse anesthetists, five surgical nurses, and five critical care nurses to confirm validity of the tool. A total of 116 providers participated in the pre-implementation questionnaire and 90 providers participated in the postimplementation survey. The pre-implementation phase took place over 3 weeks. The pre/post questionnaire assessed the following: information transfer, shared understanding, and the working atmosphere. The questionnaire consisted of a Likert scale with responses: agree, partly agree, partly disagree, and disagree. After the pre-implementation survey was completed, an information session was conducted on the standardized handoff tool. The ISBAR follows the situation, background, assessment, recommendation (SBAR) format, with the addition of identification. After completion of the information session, the tool was put into practice for 6 months. The post-implementation questionnaire asked two additional questions on staff 
compliance and staff perception on patient safety. Statistical analysis of the questionnaire revealed the overall quality of handoff significantly improved $(\mathrm{P}=0.001)$. Also, patient handoffs followed a logical structure and relevant information was relayed when using the ISBAR tool $(\mathrm{P}=<0.001)$. All staff reported perceived positive experiences with the handoff tool. Prior to implementing the ISBAR, quality patient handoffs took place $82.6 \%$ of the time. After implementation of the tool, quality patient handoffs occurred $93.3 \%$ of the time. The ISBAR handoff tool improved staff experiences and patient safety.

A prospective cross-sectional observational cohort study by Lopez-Parra et al. (2020) was conducted to evaluate whether the use of a standardized checklist would decrease loss of pertinent patient information during handoff report. This three-stage intervention took place at a referral university hospital in Spain. The project included an observation period of three days examining 59 handovers to evaluate the quality and type of patient handoff. During this observation period, information was gathered on the amount of time used for handoff, the number of interruptions, and the relevance of information transferred during patient handoff. PACU nurses were then asked questions relating to the quality of the handoff report and their ability to recall patient information. The second stage involved education on the standardized handoff tool to anesthesia providers, PACU nurses, and operative room (OR) staff. The handoff tool was then implemented into practice for a total of 12 months. The handoff checklist included four broad categories, with fifteen subgroups. The four categories included: patient identification data/basic information, anesthesia information, procedure information, and postoperative plan. The subgroups included: name, age, weight, known allergies, relevant medical history, type of anesthesia, anesthetic complications, intraoperative medication given- dose and administration time, type of procedure, drains, catheters, surgical complications, postoperative treatment, 
antithrombotic prophylaxis, postoperative pain control, and additional tests to be performed. The post-implementation data collection examined 63 handovers over two days. The results concluded that relevant patient information was communication in $92.1 \%$ of patient handovers when the checklist was utilized. Prior to the use of the standardized checklist, only $8.5 \%$ of handoff reports were complete with appropriate and relevant information. Before implementing the handoff tool, information transfer was chaotic and had frequent interruptions. Less interruptions occurred following implementation of the checklist.

The QI study by Lambert and Adams (2018) utilized a quantitative pre/post intervention design to investigate the impact of a standardized handoff tool on the quality of information being transferred. This study took place at a 350-bed hospital in the southeastern region of the United States. Two tools were used to evaluate the study: the Anesthesia Handoff Communication (AHC) survey and the Targeted Solutions Tool (TST). Both anesthesia providers and PACU nurses used these tools to provide feedback on the intervention. A total of 22 CRNAs and 15 PACU RNs were involved in this project. The handoff tool was piloted by 3 CRNAS and the project author for 4 weeks prior to being implemented into practice. Next, the pre-implementation surveys took place over approximately 4 weeks. The AHC survey evaluated current satisfaction with the handoff process. The TST analyzed the handoff process for inadequacy as well as omission of patient details. Following the pre-implementation phase, an education session was conducted, and the Written Handoff Anesthesia Tool (WHAT) was implemented into practice for approximately 2 weeks. The WHAT handoff tool included information on the following: patient information, anesthetic, history, labs, IVs/lines, medications, intake and output, post-op, and questions from receiving staff. The postimplementation survey was completed approximately 3 weeks after implementation of the 
WHAT handoff tool. Results using the AHC surveys concluded an increase in staff satisfaction for both anesthesia providers $(P<0.001)$ and PACU nurses $(P=0.001)$ after implementation of the tool. Using the TST, handoff rated as "defective" was decreased by $40 \%$, following the implementation of the WHAT. Additionally, perception of handoff adequacy by CRNAs and PACU RNs improved $(\mathrm{P}=<0.0001)$. Standardization of handoff communication improved adequacy and completeness of patient handoff in this project.

Halterman et al. (2019) implemented a QI project at a 478-bed level 1 trauma center in Eastern Georgia. This project utilized a pre and post implementation design to evaluate the impact of a standardized checklist in the PACU. The objectives for this project included increasing knowledge of patient information during transition postoperatively and maintaining continuity of care. Information for this project was tracked using the handoff assessment form. This form contained five data points including procedure, allergies, input and output, antiemetic administration, and lines and catheters. The SBAR format was selected as a guide for the handoff tool due to its use in other departments of the hospital. The SBAR pneumonic stands for situation, background, assessment, and recommendations. A target goal of $70 \%$ compliance was chosen for this QI project. The pre-implementation phase took approximately one week; results were recorded and revealed to the interdisciplinary team consisting of 4 PACU nurses, 2 CRNAs, 2 anesthesiologists, 2 resident anesthesiologist, and 3 QI nurses. Next, education on the SBAR handoff tool was provided to all staff involved in postoperative patient handoff. The SBAR tool was implemented into practice by means of laminated cards in each of the PACU rooms, a badge card for the provider's ID badge, and a mirrored handoff report sheet for PACU nurses to transcribe notes. The "situation" included the patients name, procedure and diagnosis, and allergies; "background" included past medical history, significant labs, notable baseline vital 
signs, and baseline neurological status; the "assessment" included anesthesia type, medications given, pain management plan, intravenous catheters (IVs), intake and output, and surgical/anesthetic issues; lastly, the "recommendation" included additional questions, abnormal results and patient destination. The post-intervention phase began several days after the SBAR was implemented into practice and lasted for one week. Two months later, continued compliance of the SBAR handoff tool was assessed. In this study, 78 patient handoffs were evaluated. Results revealed data omission decreased from $19.2 \%$ to $2.2 \%$ following implementation of the SBAR. Completeness of report increased from $13 \%$ to $82 \%$ after the handoff tool was implemented into practice. This project concluded use of the standardized handoff tool improved the transfer of patient information in the PACU.

The study by Bruno et al. (2017) examined the impact of implementing an evidencebased handoff checklist during patient handoff between CRNAs and PACU nurses. The goal of the project was to improve the transfer of pertinent patient information by developing a handoff tool using evidence-based practice (EBP). This project took place at a 251-bed facility in Western Pennsylvania. The study design utilized a pre/post intervention with participants involved with patient handover in the PACU; this included both CRNAs and PACU nurses. To address gaps in the current handoff procedure at the hospital, a root cause analysis was completed. From these results, the Handoff Accuracy Scoring Tool (HAST) was developed to measure accuracy of the standardized handover checklist. The HAST tool included preoperative, intraoperative, and postoperative information. The first phase of the project involved an observation of 20 handover reports in the PACU. The HAST was used to assess accuracy of the handoff report. The next phase involved developing the handoff tool with information from the HAST used as a guide. The standardized handoff tool included the following information: 
surgical procedure, complications, type of anesthesia, anesthesia difficulties, allergies, diabetic information (if applicable), history of postoperative nausea/vomiting, past medical history, malignant hyperthermia history, nerve block or catheters, pertinent medications, estimated blood loss, IV fluids, IVs/catheters, urinary output, local anesthetics, vasopressors, narcotics, and postoperative orders. The second phase involved a chart review of 20 handoffs that used the standardized handoff tool during report. Overall, a total of 40 handovers were observed and included in the evaluation: 20 for the pre-intervention and 20 for the post-intervention. Results concluded that use of a formal checklist produced more complete handoff reports $P<0.0001$.

\section{Literature Review Synthesis}

All six studies evaluated the effects of implementation of a standardized handoff tool in the PACU. Among the studies, five utilized a pre/post intervention design (Halterman et al., 2019; Lambert \& Adams, 2018; Leonardsen et al., 2019; Bruno et al., 2017; Robins \& Dai, 2015). One study compared two groups at the same time; one group utilized the handoff tool while the other group utilized current handoff practices (Robins \& Dai, 2015). All studies showed an improvement in transfer of information during anesthesia handoff with use of a standardized process (Halterman et al., 2019; Lambert \& Adams, 2018; Leonardsen et al., 2019;

Robins \& Dai, 2015; Bruno et al., 2017; Lopez-Parra et al., 2020). Two QI projects examined staff perception (Leonardsen et al., 2019; Lambert \& Adams, 2018). One study examined time as a variable (Robins \& Dai, 2015).

Among the studies, the primary difference was the standardized handoff tool. The study by Robins \& Dai (2015) used a checklist that was created by anesthesia and PACU in the facility; the study by Leonardsen et al. (2019) used the ISBAR handoff tool; the study by Halterman et al. (2019) used the SBAR format; Lopez-Parra et al. (2020) implemented a handoff 
tool that was formulated based on a literature search; Lambert and Adams (2018) implemented the WHAT handoff tool; lastly, Bruno et al. (2017) used a handoff checklist based on the HAST tool.

The projects varied in length of time. In the study by Leonardsen et al. (2019), the project took approximately seven months from the pre-implementation phase through the post implementation phase. In the study by Lopez-Parra et al. (2020), the first phase of the project took three days, the second phase took 12 months, and the third stage took two days. The total time for the study by Lambert and Adams (2018) was approximately seven weeks. In two of the studies, the length of the project was approximately 3 months (Halterman et al., 2019; Bruno et al., 2017). In the study by Robins \& Dai (2015), the length of the project was not reported.

Various strengths were noted among the studies. In the study by Robins \& Dai (2015), randomization of participants occurred during allocation of staff into one of two groups. The study by Leonardsen et al. (2019), assessed the validity of the handoff tool with 15 providers prior to being implemented into practice. Data collection was carried out on different days in the study by Lopez-Parra et al. (2020) to decrease the chance of evaluating the same providers; this study took place over 12 months. Two different tools were used to evaluate the success of the intervention in the study by Lambert and Adams (2018). In one of the studies, data collection on handoff report was blinded to anesthesia staff to reduce bias (Halterman et al., 2019). All the studies had an adequate sample size of greater than or equal to 30 participants and/or handoff reports.

A few limitations were noted among the six QI projects. In the study by Robins \& Dai. (2015), PACU staff feedback was subjective and had the potential to vary among nurses. In the study by Leonardsen et al. (2019), different personnel were evaluated during the pre and post 
implementation phases. In the study by Lopez-Parra et al. (2020) observation of PACU handoff took place only in the morning. In three of the studies, a possible Hawthorne effect could have biased the results (Leonardsen et al., 2019; Lambert \& Adams, 2018; Halterman et al., 2019). In the study by Bruno et al. (2017), a limited number of CRNAs participated in the study. Comparison and analysis of various handoff tools was not performed in any of the studies; each study evaluated the impact of one handoff tool.

A gap in knowledge on the handoff process exists because of lack of a universal standardized handoff tool. All six of the QI projects utilized a different handoff checklist/tool between anesthesia providers and PACU nurses. Each study customized the handoff tool to meet the specific needs at the facility of implementation.

\section{Rationale}

\section{Theoretical Framework}

The theoretical framework that guided this QI project was Kotter's eight step change model. The steps included urgency, team selection, vision and strategy, communicating the vision, empowerment, short-term wins, ongoing persistence, and making it stick (Melnyk \& Fineout-Overholt, 2018). This framework was selected because it detailed how to effectively implement a practice change at a systems level. The eight steps follow a logical progression from start to finish. The next paragraph will discuss application of the framework to this DNP project.

Urgency. The first step was to identify the urgency of the problem. In relation to this project, the urgency was to improve the safety and wellbeing of patients undergoing surgery. Patients are vulnerable in the postoperative period due to residual effects of anesthesia. Without a standardized handoff process in place, patient information may be missed or forgotten. There 
was an urgency to improve the handoff process to better care for patients throughout the surgical period.

Guiding the Team. The second step was to identify the guiding team. The team for this project includes the CRNAs, PACU nurses, PACU nurse manager, director of perioperative services, and CRNA lead educator at the facility, as well as the project designer, and faculty of record (FOR). This team was selected because each member plays an important role in the practice change. The project designer, FOR, and CRNA lead educator were involved in the development of the practice change and the timeline for implementation. Approval from the PACU nurse manager and director of perioperative services was attained prior to implementation. The CRNAs and PACU nurses actively implemented the process firsthand. The project designer gathered data on a weekly basis and tracked the progress of the project.

Vision and Strategy. The third step was to build a vision. The vision of the project was to implement an EBP initiative to improve transition of care throughout the perioperative setting. Improvement in transition of care can impact patient safety, provider satisfaction, and staff expectations.

Communication and Buy-In. The fourth step was to address provider buy-in. This step involves encouraging staff to accept the new practice change by incorporating it into their daily routines. Provider buy-in was accomplished through open discussion of the project's strengths and weaknesses. Clear expectations were relayed to encourage staff participation.

Empowerment. The next step was empowering the action. This step involved education on standardization of handoff communication. Discussion of positive outcomes associated with EBP encouraged its use. This step took place during the staff education session. 
Short-Term Wins. The sixth step was to create short term wins. Short term wins motivate staff adherence. A complementary lunch was provided to all staff involved in the QI project in appreciation for their participation.

Persistence. The seventh step was ongoing persistence. The project began with an observation day prior to implementation of the practice change. The QI intervention was selected to meet the specific needs at the facility. This project required ongoing persistence, by both the CRNAs and the PACU RNs, to facilitate a new process in the unit.

Making It Stick. The final step was making the change stick. Two interventions encouraged sustainability of the project. First, the SBAR handoff report tool was laminated and placed in each room of the PACU. Second, disposable paper handoff reporting forms were made available to staff who preferred handwriting the information.

\section{Specific Aims}

Purpose

The purpose of this project was to implement standardized handoff reporting between CRNAs and PACU nurses in the PACU at a healthcare system in Western Maryland.

Specific Aim 1. Evaluate the usefulness of SBAR handoff reporting among CRNAs and PACU RNs.

First Objective. Improve communication of standardized information from CRNAs to PACU RNs in the handoff report.

Second Objective. Improve satisfaction of the PACU staff and CRNAs with handoff reporting.

Specific Aim 2. Evaluate the effects of implementing SBAR in a PACU handoff report on patient safety. 
First Objective. Improve allergy reporting AEB inclusion in PACU handoff report.

Second Objective. Improve reporting of airway assessment and access AEB by inclusion in PACU handoff report.

Third Objective. Improve clarification AEB CRNA asks if PACU RN has any questions at end of handoff report.

\section{Methods}

\section{Context}

This project took place in the PACU at a 211 bed, level III trauma center in Western Maryland. This healthcare system offers various surgical interventions including cardiothoracic, orthopedic, neurosurgery, trauma, and robotic surgery. Project participants included all CRNAs, PACU nurses, and 3 nurse anesthetist students directly involved in postoperative patient handoff. A total of 37 participants were involved in this project.

\section{Intervention}

\section{Alignment of the Intervention with Specific Aims}

This project involved implementation of a standardized handoff tool to improve consistency in handoff reporting between CRNAs and PACU nurses. The standardized handoff tool selected for this project follows the SBAR format, refer to appendix C. The SBAR handoff tool was selected due to its well-known format as well as its recognition by the Joint Commission. This tool was utilized in the literature study by Halterman et al. (2019) and was confirmed valid and reliable for handoff between CRNAs and PACU RNs before its use. Permission by the author, Halterman, was granted for use of the SBAR handoff tool in this DNP project. 
The project took place in three phases. A pre-implementation phase, an implementation phase, and a post-implementation phase. The pre-implementation phase consisted of a baseline survey to all staff involved in postoperative patient handoff. This survey consisted of questions on the current handoff process in place at the facility. Additionally, PACU RNs completed a handoff assessment form after receiving handoff report from the CRNA. The handoff assessment form closely followed the form used in the study by Halterman et al. (2019). Informal education on the handoff assessment forms was provided to PACU RNs prior to their use. The implementation phase included a staff education session on the project, implementation of the SBAR handoff tool, and continuation of the PACU handoff assessment forms. The postimplementation phase consisted of a post-implementation survey as well as a 24-hour one day follow-up with completion of the PACU handoff assessment forms. The following paragraphs will provide precise detail on the three stages of this project.

In correlation with the study by Halterman et al. (2019), unidentified paper handoff assessment forms were completed by PACU RNs following handoff report from the CRNA. After completion, the PACU RN placed the anonymous completed handoff assessment form in a secure container located in the PACU. The handoff assessment form, used in the study by Halterman et al. (2019), evaluated inclusion of the procedure, allergies, intake and output, antiemetic, and lines/catheters during handoff report. In this DNP project, the handoff reports evaluated inclusion data such as patient and procedure identification, allergies, intake and output, (I \& O), airway, and lines/catheters. These five data points were selected by the project designer, the CRNA lead educator, and the FOR. Refer to appendix D for the handoff assessment form used in this project. The project designer contacted the author of the study, Halterman, to gain 
approval of the revised handoff assessment form. These five topics were confirmed to be valid and reliable by the project designer, CRNA lead educator, and FOR in this project.

The pre-implementation phase began in April of 2021 and lasted approximately four weeks. This phase consisted of an online anonymous pre-implementation survey on the current handoff process. This survey was emailed to the facility work emails of all staff involved in the handoff process; this included 17 CRNAs and 17 PACU RNs. The pre-implementation survey consisted of seven questions, five of which followed a 5-point Likert scale format on Qualtrics. The first question identified the provider completing the survey; this was either the CRNA or the PACU RN. Questions two through five discussed staff satisfaction, expectations, responsibility, and availability to ask questions following handoff report. The last two questions were open ended and discussed what the provider liked and disliked about the current handoff process. Refer to appendix B for the pre/post implementation survey. PACU nurses were educated on the PACU handoff assessment form during the pre-implementation phase. After receiving handoff report from the CRNA, the PACU RN completed a six-question handoff assessment form. The first question pertained to use of the SBAR handoff tool, the following five questions included patient identification, allergies, airway, intravenous lines, and intake and output. The handoff assessment form was submitted anonymously and did not include any patient or provider information/identification. After completing the handoff assessment form, the PACU RN placed the form in a designated secure container located in the nursing station in the back of the PACU.

Informal education was provided to all PACU staff on the SBAR handoff tool, as inperson staff meetings were not being held due to Covid-19. Education was provided to 2 to 3 PACU RNs at a time and discussed the PACU handoff assessment form and SBAR handoff tool. The education lasted approximately 10 minutes. Education took place on multiple days during 
the pre-implementation phase in the month of April. The PACU RNs were educated prior to the CRNAs to help decrease a possible Hawthorne effect during the pre-implementation phase. All PACU RNs directly involved in postoperative patient case were educated of the intervention. Proper understanding on how to use the handoff tool was confirmed through verbal explanation by the PACU RN.

The implementation phase began in May of 2021 and ended in July of 2021. This phase lasted approximately eight weeks. In May, the project designer presented a live educational session on specific details pertaining to a DNP project, background information on handoff communication, synthesis of literature, the SBAR intervention, and staff requirements throughout the course of the project. This education session was presented to the CRNAs during a designated staff meeting and lasted approximately 45 minutes. Refer to appendix $\mathrm{G}$ for an outline of the education session presented to the CRNAs.

Following the CRNA education session, the laminated SBAR handoff tool was placed on the side table next to the patient's bed in each PACU room. Disposable paper handoff forms were also available for use. CRNAs were instructed to use the laminated handoff tool as a guide while giving report to the PACU RN and return it to the bedside table after its use.

The final stage of the project took place in July of 2021 and lasted approximately two weeks. An anonymous post-implementation survey was distributed mirroring the 5-point Likert scale pre-implementation survey. Staff were provided with paper post-implementation survey forms. Twelve weeks after implementation of the handoff tool, a 24-hour follow-up was conducted to measure the sustainability of the intervention. On a designated day, PACU staff were instructed to complete the handoff assessment form after receiving report from the CRNA. 


\section{Benchmarks}

A standardized handoff process between providers has been shown to reduce loss of pertinent patient information. Multiple studies have confirmed the use of a standardized handoff tool to improve handoff reporting in the PACU (Bruno et al., 2017; Halterman et al., 2019; Lambert \& Adams, 2018; Leonardsen et al., 2019; Lopez-Parra et al., 2020; Robins \& Dai, 2015). In 2006, the Joint Commission recommended healthcare providers to utilize a standardized process during patient handoff to improve safety (The Joint Commission, 2006). The Joint Commission also supports the standardized SBAR format to be used to improve communication (TJC, 2013).

\section{Gaps in Evidence}

While an abundance of evidence exists on the need for a standardized process between anesthesia providers and PACU nurses, a universal handoff communication tool has not been confirmed. Each of the studies implemented a standardized handoff tool that best addressed the needs at the facility.

At the outset of this project, the project team assumed there would be information describing medication errors due to miscommunication in handoff reporting, so the team included tracking of medication errors as an objective. However, information pertaining to tracking of medication errors was not reported in the literature.

\section{Congruence with the Organization's Strategic Plan}

The mission statement at the implementation site states, "We are dedicated to providing patient-centered care and improving the health and well-being of the people in the communities we serve" (UPMC Western Maryland, 2020). Standardized handoff reporting provides a patientcentered approach because it addresses pertinent patient history, intraoperative events, and 
postoperative recovery considerations. This project is in alignment with the hospital's mission statement to provide quality patient-centered care.

\section{Technical Equipment and Instruments}

Technical equipment used in this project included a large monitor to display the PowerPoint presentation for the education session. Instruments included pre and post implementation surveys, handoff assessment forms, and the laminated/paper SBAR handoff tool.

\section{Key Personnel}

The key personnel included the project designer, the FOR, the CRNA lead educator, the CRNAs, PACU nurses, the PACU nurse manager, and the director of perioperative services.

\section{Technology}

The project designer used a designated West Virginia University (WVU) School of Nursing laptop throughout the course of the project. The laptop was used to develop the project proposal, PowerPoint education presentation, pre/post implementation surveys, and complete the project manuscript. Additionally, the laptop was used to communicate with staff via email. Pre and post implementation surveys were developed and recorded in Qualtrics. Statistical analysis of the data was process using SPSS on the WVU laptop.

\section{Budget}

The total cost of the project included approximately $\$ 375.00$ for supplies and 300 labor hours by the project designer. Primary costs were allotted toward printing and laminating the handoff communication tool and providing staff with a complementary lunch following implementation of the intervention. Printing and laminating the SBAR handoff tool cost approximately $\$ 125.00$. A complementary lunch provided to staff cost approximately $\$ 250.00$. An estimated 300 "labor hours" was associated with the development, implementation, and 
evaluation of this project. The financial costs of the project were covered at the cost of the project developer. Refer to appendix A for the project budget.

\section{Evaluation plan}

\section{Assessing the Impact of the Intervention}

The intervention was assessed through pre/post implementation surveys and the handoff assessment forms. The pre/post implementation surveys assessed staff perception on the handoff process at the time. Changes in staff perception were based on analysis of the pre/post implementation surveys. The handoff assessment form evaluated the effects of the handoff report prior to and during implementation of the SBAR handoff tool. The handoff assessment form was used to assess the correlation between use of the SBAR handoff tool and completeness of the handoff report.

\section{Project Objectives: Correlation between Project Outcomes and Intervention}

Specific Aim 1. Evaluate the usefulness of SBAR handoff reporting among CRNAs and PACU RNs.

First Objective. The first project objective was to improve communication through standardized handoff reporting from CRNAs to PACU RNs. Evidence of improved communication included the reporting of 5 standardized items shared by the CRNA during the report: patient identification, allergies, airway, intravenous lines, and intake and output. Collection methods were the pre/post implementation surveys and the PACU RN handoff evaluation forms.

Second Objective. The second objective was to improve CRNA and PACU RN satisfaction with handoff reporting as evidenced by improved met expectations of the handoff report. Data collection was completed using the pre/post implementation surveys. 
Specific Aim 2. Evaluate the effects of implementing SBAR in a PACU handoff report on patient safety.

First Objective. The first objective of specific aim 2 was to improve allergy reporting in the post-anesthesia handoff report. Data was collected on inclusion of allergies in handoff reporting. This collection was completed using the handoff assessment form and the pre/post implementation surveys.

Second Objective. The second objective of specific aim 2 was to improve reporting of airway assessment in the handoff report. Ease or difficulty of instrumenting the airway was collected using the handoff assessment form and the pre/post implementation surveys.

Third Objective. The third and final objective of specific aim 2 was to improve clarification of the report was evidenced by whether the CRNA asks PACU RN if there were any additional questions following handoff report. The outcome measure was noted as clarification and was evaluated using pre/post implementation surveys.

\section{Strategies to Achieve the Specific Aims}

The specific aims of the project include evaluation of the usefulness of SBAR handoff reporting among CRNAs and PACU RNs and evaluation of the effects of implementing SBAR in a PACU handoff report on patient safety. The strategies used to achieve these aims included collaboration and education.

The first strategy to achieve the project's specific aims was collaboration with staff. Prior to the start of the project, an informal observation day was completed. During this time, the project designer collaborated with the staff to identify limitations to the current handoff process in place at that time. The project designer was then able to identify a proposed plan to meet the specific needs of the facility. The project designer maintained open communication with staff 
throughout the course of the project and adjusted the project as necessary. During implementation, a few suggestions were made by staff to improve the practicality of the project. First, staff voiced an interest in having disposable SBAR handoff tools available in addition to the laminated tools in the PACU. To improve staff compliance with the intervention, disposable paper SBAR handoff tools were placed in the preoperative patient area. Second, postimplementation surveys were made available in paper form, per staff request.

Peer reviewed literature was disseminated to staff on postoperative handoff reporting. This education highlighted the usefulness and applicability of standardization during handoff in the PACU, as well as its impact on patient safety. The project designer reinforced this information throughout the course of project. Additionally, education was provided on how to use the handoff tool, where to find it, and how to complete the handoff assessment forms.

The usefulness of the intervention and its impact on patient safety, through the strategies of collaboration and education, were measured through the pre/post implementation survey and the handoff assessment form. The pre/post implementation survey addressed the questions: "the current method of handoff reporting meets my responsibility for safe patient care" and "the current method of handoff reporting meets my expectations". The impact of education was measured by completion of all five questions in the handoff assessment forms.

\section{Measures}

\section{Measures for Studying Processes and Outcomes}

The measures used for studying the outcomes of the intervention included the pre/post implementation surveys and the handoff assessment forms. Validity and reliability of the SBAR handoff tool and handoff assessment form was confirmed in the study Use of a Checklist for the Postanesthesia Care Unit Patient Handoff by Halterman et al. (2019). In this study, an 
interdisciplinary committee with stakeholders consisting of anesthesiologists, CRNAs, resident anesthesiologists, and PACU RNs formulated the SBAR handoff tool and handoff assessment form. The SBAR handoff tool used in this DNP project followed the same format used by Halterman et al. (2019). The handoff assessment form included four of the five items listed in the study by Halterman et al. (2019). One modification was made to the handoff assessment form; this modification included airway assessment instead of antiemetics. Validity and reliability of the pre/post implementation surveys and the PACU handoff assessment form were confirmed by the project designer, FOR, and CRNA lead educator at the site of implementation. The SBAR handoff tool was chosen for this project because of its simple, yet precise format. Other handoff tools found in the literature appeared complicated and difficult to use. The SBAR format is well known and strongly supported by the Joint Commission.

\section{Contextual Elements: Success}

A contextual element that contributed to the success of the project was the staff's support of the DNP project. The anesthesia department welcomed improving patient safety by means of a QI initiative. Though other units in the hospital use standardized handoff reporting, it was not in place among anesthesia and PACU staff prior to the intervention. This created an opportunity to improve the current process in place. Another element that contributed to the success of the project was the project designer's familiarity with the hospital staff due to prior employment. The project designer had professional working relationships with the perioperative staff prior to the implementation of the project, which helped encourage collaboration throughout the QI initiative. 


\section{Contextual Elements: Limitations}

Whereas staffs of large academic centers are familiar with research and quality improvement endeavors, one factor that may have inhibited the success of the project was the staff's unfamiliarity with the concept of a DNP project. This project was one of the first to be implemented in the anesthesia department at the facility. Another contextual element that limited the success of the project was COVID-19. The pandemic created unique challenges for the project such a limited availability for staff meetings, increased employee turnover rates, and delays in elective surgery due to infection from the COVID-19 virus.

\section{Contextual Elements: Efficiency}

The efficiency of the project was influenced by the number of staff involved in postoperative patient handoff. There were 34 staff members and 3 nurse anesthetist students directly involved in patient handoff in the PACU. Due to the small group of staff, education on the initiative was completed in a comprehensive and timely manner. Additionally, the project designer was completing a clinical rotation in the anesthesia department at the time of implementation, which facilitated collaboration and reinforcement on a weekly basis.

\section{Contextual Elements: Costs}

Minimal costs were associated with this QI project. The project designer provided the laminated SBAR handoff tool, pre/post-implementation surveys, and handoff assessment forms. The project did require some labor hours for staff throughout the course of implementation. The PACU RNs completed the handoff assessment forms after receiving handoff report. It is estimated that each handoff assessment form took approximately 15 seconds to complete. CRNA education was completed during a routine staff meeting and education to the PACU RNs was completed during regular work hours. Additionally, staff participated in pre/post-implementation 
surveys which took approximately 5 minutes to complete. No reoccurring costs will be required for sustainment of the intervention.

\section{Methods to Assess Data Completeness and Accuracy}

The data assessed in this project included the pre and post implementation surveys and the PACU evaluation forms. The pre and post implementation surveys were based on staff perception of the current handoff practice at that time. Completeness of the pre and post implementation surveys were determined by staff answering all seven questions. Because surveys were based on staff perception, all answers were accepted as accurate. PACU handoff assessment forms were deemed complete when all five items had been answered. Accuracy was determined by PACU RNs demonstrating how to fill out the form after receiving report.

\section{Analysis}

Statistical analysis was completed on two data sets in the project: pre and post implementation surveys and handoff assessment forms. The pre and post implementation surveys had five quantitative questions following a five-point Likert format and two open ended qualitative questions. The handoff assessment forms had six quantitative yes/no questions. WVU's statistician was consulted prior to completing the statistical analysis. Appropriate tests were determined for the two data sets. Results were processed using SPSS. Statistical analysis was completed for the pre and post-implementation surveys using the Mann-Whitney U test. This test was selected because the results were based on a 5-point Likert scale and consisted of ordinal data. Additionally, the data was unpaired and did not follow a normal distribution pattern. The Mann-Whitney U test was used to determine statistical significance of handoff completion during the pre-implementation phase and implementation phase. Again, results in this data set were unpaired. Results with a $P$ value of less than 0.05 were considered statistically 
significant. Data analysis was completed on results over a 13-week period to evaluate the effects of the intervention over time.

\section{Ethical Considerations}

This project did not involve human research or patient participation. Pre and post implementation survey results remained anonymous. PACU evaluation forms did not reveal patient or provider identification. The participants involved in postoperative handoff had the right to refuse to participate in this project.

\section{Results}

\section{Results}

\section{Evolution of the Intervention}

The DNP project proposal included a three-phase implementation plan consisting of a pre implementation phase, an implementation phase, and a post implementation phase. The pre implementation phase was originally determined to begin in January of 2021 with a staff education session. This was to be followed by a pre implementation survey and implementation of the handoff assessment forms in the PACU. The project designer was to begin collecting QI tracking data on medication errors. In February of 2021, the QI initiative was to be implemented into practice for 8 weeks. Additionally, handoff assessment forms were to be completed, as well as QI tracking on medication errors. The post-implementation phase was then scheduled to take place in April of 2021. This was to include a post implementation survey, continuation of QI tracking on medication errors, and a one day 24-hour follow up with completion of the handoff assessment forms. The project designer was to be physically present on a weekly basis to help guide the project and collect the handoff assessment forms. 
The project was delayed by three months due to the project designer being unable to be physically present on a weekly basis throughout the project. The timeline was adjusted according to the project designer's clinical rotation schedule at the hospital site. The project's pre implementation phase began in April of 2021 with pre implementation surveys and handoff assessment forms. This phase lasted approximately four weeks. The SBAR intervention phase was implemented into practice in May of 2021. The implementation phase lasted eight weeks through July of 2021. PACU RNs completed handoff assessment forms during this time. The post implementation phase took approximately one week and was completed in July of 2021 . Refer to appendix $\mathrm{H}$ for a complete timeline table of the intervention and its progression.

The following modifications were made to the intervention during the project. First, post implementation surveys were made available to staff in paper form rather than via online surveys. Multiple staff members voiced difficulty receiving the survey through their hospital work email. Second, SBAR handoff tools were made available in paper form in addition to the laminated version, per staff request.

\section{Process Measures and Outcome}

The process measures for the project included pre and post implementation surveys and a handoff assessment form to evaluate the EBP initiative. The pre and post implementation surveys measured staff perception before and after implementation of the standardized process. The surveys consisted of seven questions. These questions included professional title, provider satisfaction, provider expectations, responsibility for safe patient care, an opportunity to answer questions after report, and likes/dislikes about the current handoff process in place.

There was a total of 30 completed surveys: 15 pre-implementation and 15 postimplementations surveys. For the pre-implementation survey, the respondents included 3 
CRNAs, 5 PACU RNs, and 7 anonymous responses. For the post-implementation survey, the respondents consisted of 9 CRNAs and 6 PACU RNs.

It was difficult to pair pre- and post-surveys, so survey data were aggregated. Statistical analysis using the Mann-Whitney $U$ test was completed on the pre/post-implementation survey questions pertaining to staff satisfaction, expectations, responsibility for safe patient care, and the opportunity to answer questions after report. These four questions followed a 5-point Likert format consisting of responses: "strongly agree", "somewhat agree”, "neither agree nor disagree", "somewhat disagree", and "strongly disagree". The pre/post- implementation surveys each consisted of 15 responses. Refer to appendix L for table on the pre/post-implementation survey results.

Satisfaction. The results on staff satisfaction were not statistically significant $(P$ value of 0.083), however there was in an improvement in staff satisfaction. In the pre-implementation survey 4 participants rated staff satisfaction as "strongly agree", 9 participants rated it as "somewhat agree", and 2 participants rated it as "neither agree nor disagree". In the postimplementation survey 7 participants rated satisfaction as "strongly agree" and 8 participants rated it as "somewhat agree".

Expectations. An improvement in provider expectations were noted and statistically significant with a $P$ value was 0.012 . In the pre-implementation survey 4 participants rated the provider expectation question as "strongly agree", 7 participants rated it as "somewhat agree", and 3 participants rated it as "neither agree nor disagree". In the post implementation survey, 10 participants rated provider expectations as "strongly agree" and 5 participants rated it as "somewhat agree". 
Safe Patient Care. Question four assessed the providers responsibility for safe patient care. The $P$ value for this variable was statistically significant with a value of 0.006 . In the preimplementation survey 4 providers rated responsibility for safe patient care as "strongly agree", 7 rated it as "somewhat agree", 1 participant rated it as "neither agree nor disagree", and 3 rated it as "somewhat disagree". In the post-implementation survey 11 participants rated it as "strongly agree" and 4 rated it as "somewhat agree".

Opportunity to Answer Questions. Following implementation of the SBAR handoff tool there was an improvement in the opportunity to answer questions after report. The $P$ value statistically significant at 0.005 . For the pre-implementation survey 8 participants rated an opportunity to answer questions after report as "strongly agree", 6 rated it as "somewhat agree", and 1 participant did not answer the question. In the post-implementation survey, all 15 participants rated it as "strongly agree".

Likes and Dislikes. The final 2 questions in the survey addressed staff likes and dislikes on the current handoff process. In the pre-implementation survey, staff stated likes to be quick, provider to provider, thorough report with ample time for questions, and efficient". Other staff commented in the likes section on their dislikes of the current handoff process. The comments included a desire for a more standardized approach and reports lack consistency. In the dislikes section, staff commented that it is hurried, things get missed, not everyone uses handoff to the fullest potential, it varies greatly, minimal information is provided, inconsistency, changes in staff during middle of report, and staff not listening closely. Another comment included the OR $\mathrm{RN}$ also calls report in addition to anesthesia.

In the post-implementation survey, likes included handoff covers everything that is pertinent to anesthesia, communicates important information in a timely manner, more organized 
and structured, standardized among providers, covers all information, is detailed, open conversation with option to answer questions, standardized expectations, and concise. The dislikes included it sometimes is rushed, distractions, variations in handoff depending on the CRNA, inconsistent at times, can be hit or miss, and time-consuming. Refer to appendix I for tables on the likes and dislikes associated with the handoff process in the pre and postimplementation phases.

Handoff Assessment Tool. The handoff assessment tool assessed CRNA compliance with the SBAR handoff tool and completeness of handoff report. The 5 categories in the handoff assessment tool were patient and procedure identification, allergies, intake and output, airway, and lines/catheters.

The following data corresponds to the percentage of reporting in each category during the pre-implementation phase: patient and procedure identification- $87.6 \%$, allergies- $82.5 \%$, I \& O77.3\%, airway $-50.5 \%$, and lines/catheters $-28.9 \%$. In the post-implementation phase, 36 handoffs were evaluated. The SBAR handoff tool was used in $72.2 \%$ of handoffs. The following data represents the percentage of reporting during the implementation phase: patient and procedures- $94.4 \%$, allergies $-83.3 \%$, intake and output $-94.4 \%$, airway $-69.4 \%$ and lines and catheters $-66.7 \%$. There was an overall improvement in all 5 categories with use of the SBAR handoff tool.

\begin{tabular}{|c|c|c|c|c|c|c|}
\hline \multicolumn{7}{|c|}{ Pre-implementation } \\
\hline $\begin{array}{c}\text { 97 Handoff } \\
\text { Forms }\end{array}$ & SBAR & $I D$ & Alleries & $1 \& O$ & Airway & $\begin{array}{c}\text { Lines/ } \\
\text { catheters }\end{array}$ \\
\hline Yes & $0(0 \%)$ & $85(87.6 \%)$ & $80(82.5 \%)$ & $75(77.3 \%)$ & $49(50.5 \%)$ & $28(28.9 \%)$ \\
\hline No & $97(100 \%)$ & $12(12.4 \%)$ & $17(17.5 \%)$ & $22(22.7 \%)$ & $48(49.5 \%)$ & $69(71.1 \%)$ \\
\hline
\end{tabular}




\begin{tabular}{|c|c|c|c|c|c|c|}
\hline \multicolumn{7}{|c|}{ Implementation } \\
\hline $\begin{array}{c}36 \text { Handoff } \\
\text { Forms }\end{array}$ & SBAR & $I D$ & Alleries & $I \& O$ & Airway & $\begin{array}{c}\text { Lines/ } \\
\text { catheters }\end{array}$ \\
\hline Yes & $26(72.2 \%)$ & $34(94.4 \%)$ & $30(83.3 \%)$ & $34(94.4 \%)$ & $25(69.4 \%)$ & $24(66.7 \%)$ \\
\hline No & $10(27.8 \%)$ & $2(5.6 \%)$ & $6(16.70 \%)$ & $2(5.60 \%)$ & $11(30.60 \%)$ & $12(33.3 \%)$ \\
\hline
\end{tabular}

The one day follow up assessed compliance with the intervention. There was a total of 5 completed handoff assessment forms. In these 5 handoff assessment forms, none of the providers used the SBAR handoff tool during patient handoff. Patient and procedure identification was included in $80 \%$ of handoffs, allergies were reported $100 \%$ of the time, $40 \%$ of handoffs included intake and output, and lines and catheters were included $40 \%$ of the time. This data can also be found in appendix $\mathrm{J}$.

\begin{tabular}{|c|c|c|c|c|c|c|}
\hline \multicolumn{7}{|c|}{ Post-implementation } \\
\hline $\begin{array}{c}5 \text { Handoff } \\
\text { Forms }\end{array}$ & SBAR & $I D$ & Alleries & I \& O & Airway & $\begin{array}{c}\text { Lines/ } \\
\text { catheters }\end{array}$ \\
\hline Yes & $0(0 \%)$ & $4(80 \%)$ & $5(100 \%)$ & $5(100 \%)$ & $2(40 \%)$ & $2(40 \%)$ \\
\hline No & $5(100 \%)$ & $1(20 \%)$ & $0(0 \%)$ & $0(0 \%)$ & $3(60 \%)$ & $3(60 \%)$ \\
\hline
\end{tabular}

Completeness of handoff report was determined by inclusion of the 5 categories: patient identification and procedure, allergies, I \& O, airway, and lines/catheters. The preimplementation phase consisted of 97 handoff assessment forms; 2 did not include any of the 5 categories, 7 included 1 category, 17 included 2 categories, 28 included 3 categories, 23 included 4 categories, and 20 included all 5 categories. During implementation of the SBAR handoff tool, there were 36 completed handoff assessment forms; 2 included 1 category, 5 included 2 categories, 5 included 3 categories, and 24 included all 5 categories. The post-implementation one day follow-up had 5 handoff assessment forms. Of the 5 forms, 1 included 2 categories, 2 included 3 categories, and 2 included all 5 categories. 
During pre-implementation, handoff reports including 3 of the 5 categories were most frequently noted. In comparison, handoff reports including 5 of the 5 categories were most frequently seen during the implementation phase. During the one-day follow-up, $40 \%$ of the handoffs included 3 of the 5 categories and $40 \%$ included 5 of the 5 categories. Refer to appendix $\mathrm{K}$ for a graph and table of the data.

Statistical analysis was performed in SPSS using the Mann Whitney U test to determine statistical significance of handoff form completeness. The $P$ value was 0.001 , therefore there was a statistically significant improvement in handoff completeness in the implementation phase.

The outcome associated with this project included an overall improvement in staff perception on handoff reporting and an improvement in completeness of handoff reporting from CRNAs to PACU RNs with use of the SBAR handoff tool.

\section{Contextual Elements Associated with the Intervention}

Standardized handoff reporting was being used in other departments of the hospital, including among RNs involved in the perioperative department. However, there was not a standardized process in place between CRNAs and PACU RNs in the postoperative period. Due to standardized handoff reporting being positively recognized throughout the facility, the project was found applicable and useful. The CRNAs at the facility welcomed QI initiatives to the department.

\section{Observed Associations}

Observed associations of improvement in handoff reporting correlated with implementation of the intervention. An overall improvement in staff perception on handoff reporting was observed after implementation of the SBAR handoff tool. When the SBAR 
handoff tool was used in practice and evaluated by the PACU RNs, an improvement in handoff completeness was observed.

\section{Unintended Consequences}

There were a few unintended consequences associated with the project. First, one unexpected problem included a decrease in the completion rate of handoff assessment forms during the implementation phase. In the pre implementation phase there were 97 handoff assessment forms completed by the PACU RNs. This phase took 4 weeks. During the implementation phase, which consisted of an 8-week period, only 36 handoff assessment forms were completed. Second, another unintended problem was communication with staff via email. The CRNAs stated the department was in a transition period of allocating new work email addresses. The hospital had recently become affiliated with a new organization. Due to the confusion associated with the emails, post implementation surveys were made available in paper form. Third, the estimated total costs associated with the project were originally estimated to be $\$ 200.00$. The project costs ended up totaling to $\$ 375.00$. Printing and laminating the SBAR handoff tools and printing the handoff assessment forms were originally estimated to cost $\$ 50.00$. The cost associated for the project supplies ended up totaling to $\$ 125.00$. The estimated cost for the complementary lunch was estimated to be $\$ 150.00$ but ended up costing $\$ 250.00$. An unintended benefit associated with the project included an opportunity for the project designer to reinforce the intervention throughout the course of the project. The project designer was actively participating in clinicals on a weekly basis throughout the 13 weeks of the project. Also, despite limited in person meetings due to COVID-19, staff education and collaboration was uninhibited. 


\section{Missing Data}

An original objective was to decrease medication errors through improved reporting of certain medications such as antibiotics, acetaminophen, and time sensitive medications. This data was to be tracked by the project designer through an online database beginning in April and lasting through July. Over a 4-month period, the project designer met with multiple pharmacists, the PACU nurse manager, the director of perioperative services, the chief CRNA, and the core measures committee to discuss accessibility of this data. Due to the complexity of the tracking systems, consisting of both paper and computer charting, the information was deemed unavailable for this project. The project designer did not include medications as part of the 6 items in handoff assessment form because this data was determined to be collected via the online database. Additionally, in the study by Halterman et al., (2019), the handoff assessment form did not include medication tracking.

In the pre implementation surveys seven out of fifteen surveys did not disclose their professional title (CRNA or PACU RN). In both the pre/post-implementation surveys, some staff members did not provide qualitative answers on the likes/dislikes of the current handoff process.

\section{Discussion}

\section{Summary}

\section{Key Findings}

Standardization in handoff reporting improved the handoff process as evidenced by improvement in staff perception and handoff completeness. This project provided a process to improve patient safety by decreasing loss of valuable information during transition of patient care. The project's aims were to evaluate of the usefulness of SBAR handoff reporting among CRNAs and PACU RNs and to evaluate of the effects of implementing SBAR in a PACU 
handoff report on patient safety. The usefulness of the handoff tool was assessed through the handoff assessment form and the pre and post implementation surveys. The measure used to evaluate usefulness included improved communication as evidenced by inclusion of the five elements of handoff reporting (patient and procedure identification, allergies, intake and output, airway, and intravenous lines and catheters). The measure used to evaluate satisfaction included an assessment of provider satisfaction with the handoff process; this question stated, "I am satisfied with the current handoff process in the PACU".

The second aim was to evaluate the effects of SBAR on patient safety. Patient safety was assessed through use of the handoff assessment form and the pre and post implementation surveys. The handoff assessment form evaluated the impact of SBAR on patient safety by assessing reporting of allergies and airway difficulty. Improvement in clarification was evaluated through comparison of pre and post implementation surveys; this question stated, "An opportunity to answer any additional questions is offered at the end of the handoff report".

\section{Project Strengths}

Multiple strengths were associated with this DNP QI project. First, the SBAR handoff tool improved patient safety by improving handoff reporting. Inclusion of all elements in the SBAR handoff tool during report will improve the quality and consistency of the information being transferred. Second, the process provided staff with a reusable handoff reporting tool. This encourages sustainability of the intervention over time. Third, there were no financial deficits associated with the project. The project designer provided the PACU with a handoff reporting tool. Additionally, there are no recurring costs required by the department. Fourth, the project encouraged collaboration between CRNAs and PACU RNs. Common expectations were created during postoperative handoff, improving transition of care from one provider to another. Fifth, 
the initiative increased the awareness of a DNP project. The DNP project differs from other projects as the aim is to implement a systems level change to a facility. Creating awareness increases the prospect of other DNP projects being implemented at the facility. Lastly, the project was designed to meet the specific needs identified at the facility. Prior to implementation of the project, problem areas were identified and targeted. The handoff tool was selected to address those concerns and improve the current process in place.

\section{Interpretation}

\section{Association between the Intervention and the Outcomes}

The results of the pre and post implementation surveys suggest an improvement in handoff reporting to be the result of the SBAR handoff assessment form. Improvement in staff expectations, responsibility for safe patient care, and the opportunity to answer additional questions at the end of handoff report resulted in a $P$ value of $<0.05$. The handoff assessment forms concluded an improvement in handoff reporting with use of the SBAR handoff tool as evidenced by an increase in reporting of patient identification and procedure, allergies, I and O, airway, and IVs and catheters.

\section{Comparison of Results with other Publications}

The project's results are in alignment with the findings of other publications. The results associated with the pre and post implementation surveys in this project confirmed improvement in staff perception evidenced by a statistically significant increase in scores pertaining to staff expectations, responsibility for safe patient care, and an opportunity to answer additional questions after report. Other studies that utilized a pre and post implementation survey confirmed an improvement in handoff report with the use of a standardized handoff process (Leonardson et al., 2019). In the study by Halterman et al. (2019), 78 patient handoffs were evaluated. Data 
omission decreased from $19.2 \%$ to $2.2 \%$ and completeness of report increased from $13 \%$ to $82 \%$ with the use of the SBAR handoff tool. In the study by Lambert and Adams (2018), 229 baseline forms were completed along with 217 post-implementation forms. Results revealed a $60.7 \%$ defective rate of handoff from CRNA to PACU RN prior to implementation of the handoff tool. This decreased to $36.4 \%$ defective rate after implementation of the WHAT handoff tool. In the study by Leadonardson et al. (2019), the ISBAR handoff increased the patient handover quality from $82.6 \%$ to $93.3 \%$. The number of handoffs assessed was not revealed. In the study by Lopezparra et al. (2020), 59 handoffs were assessed prior to implementation of the handoff tool and 63 were assessed after implementation. Results revealed an improvement in communication and transfer of relevant information with the use of a surgical checklist. In the study by Bruno et al. (2017), 20 handoffs were examined during pre-implementation and 20 handoffs were examined after implementation of the handoff tool. A significant improvement was noted to be found for the checklist handoff score after implementation of the handoff tool. In this study, 138 handoffs were evaluated. Data omission associated with patient and procedure identification decreased from $12.4 \%$ to $5.6 \%$. Omission of allergy reporting decreased from $17.5 \%$ to $16.7 \%$. Omission of intake and output decreased from $22.7 \%$ to $5.6 \%$. Airways assessment omission decreased from $49.5 \%$ to $30.6 \%$. Lines and catheter omission decreased from $71.1 \%$ to $33.3 \%$. The one-day follow-up showed an improvement in reporting of allergies (82.5\% to 100\%), intake and output ( $77.3 \%$ to $100 \%)$, and lines and catheters $(28.9 \%$ to $40 \%)$ compared to the pre-implementation phase.

\section{Impact of the Project on People and Systems}

The clinical relevance of the project pertained to an overall improvement in provider satisfaction as well as an improvement in postoperative patient handoff from CRNAs. Overall, 
the standardized handoff tool positively impacted staff perception toward handoff reporting as evidenced by improvement in post-implementation survey results. With use of the SBAR tool, an increase in completeness in handoff reporting was seen. This project brought awareness to the perioperative staff on the need for standardization to improve patient safety. Additionally, this project has the potential to impact other departments in the facility. SBAR is not being used in the preoperative area. SBAR handoff reporting in preop has the potential to improve the safety of patients in the intraoperative period. SBAR would identify information such as allergies, medications received in preop, past medical history, and antibiotics to be given intraoperatively.

\section{Rationale for Varying Outcomes}

A difference between the observed outcomes and the anticipated outcomes can be attributed to the variation in handoff reporting among providers. The anticipated outcome was that every CRNA would give report following the SBAR handoff tool, however this was not the case. The observed outcome was that some CRNAs used the SBAR handoff tool when giving report, but others did not. Variation in handoff reporting impacted the handoff assessment form

results as well as the staff survey on staff perception. An anticipated outcome for the project was improvement in staff perception of handoff reporting and improvement in completeness with every handoff report. The observed outcome suggested an overall improvement in these two areas, however, on an individual basis not everyone was compliant with the DNP project initiative. These variations in individual experiences may have influenced the results of the project. The project's setting contributed to the outcomes associated with the project. The hospital was not familiar with the DNP project process; therefore, the staff involved were not as proficient with the change. The increased workload of the project may have impacted the degree of compliance associated with the use of the intervention. 


\section{Cost Savings}

Improving proficiency with standardized handoff reporting has the potential to decrease anesthesia time spent giving report in the PACU. Standardized handoff reporting improves patient safety by relaying consistent and pertinent information. By improving the quality of handoff reporting, a decrease in medical errors from miscommunication may occur.

\section{Limitations}

\section{Limits to Generalizability}

The project's generalizability may be limited due to the handoff tool specifically pertaining to handoff between anesthesia providers and PACU RNs in the postoperative period. This project could be replicated in the PACU at other facilities. The SBAR format may be generalizable to other units in the hospital; however, the content of the checklist would need to be adjusted to meet the handoff requirements for that unit.

\section{Threats to Internal Validity}

Various threats could influence the internal validity of the project. A Hawthorne effect may have influenced the results during the implementation phase, as CRNAs were aware of project at that point. The project designer was actively participating in a clinical rotation throughout the project and utilized the SBAR handoff tool during patient report. The project designer's handoffs were included in the handoff assessment form results during the preimplementation and implementation phase. The project did not measure paired results with the handoff assessment form and surveys; therefore, an association between the two outcomes could not be evaluated. This project took place over the course of a 13-week period. The impact over an extended period of time was not assessed. 


\section{Minimizing Limitations}

There were efforts made to minimize the limitation in the study. The CRNA education session was completed after the pre-implementation phase to decrease a possible Hawthorne affect. All pre/post implementation surveys and handoff assessment forms were anonymous to limit bias. The sample size of the population was greater than 30 participants. The project design closely followed the study performed by Halterman et al. (2019).

\section{Conclusion}

\section{Usefulness of the Intervention}

Standardization of patient handoff using the SBAR handoff tool creates an opportunity to improve transition of care in the postoperative period. The handoff tool may be useful to help relay appropriate information regarding the intraoperative anesthetic and its influence on postoperative recovery. Based on the results of the project, implementation of handoff reporting could be recommended.

\section{Sustainability}

The sustainability of the QI is dependent on the willingness of the CRNA to implement the handoff tool into daily practice. The handoff tool was made available for long term use. The initiative should be continued to improve patient safety and maintain provider satisfaction. This initiative is in congruence with the organization's strategic plan to provide patient centered care by utilizing EBP into daily practice. The project could be expanded by creating a mirror handoff tool for the CRNA's badge as described in the study by Halterman et al. (2019). Barriers to the use of the intervention include staff nonadherence and unfamiliarity by newly hired staff. The CRNAs at the facility have the option to incorporate the handoff tool into their practice, but it is not required. Some staff may resort back to previous handoff methods. Newly hired staff may be 
unfamiliar with the SBAR handoff tool, ultimately limiting its use. The current and future stakeholders in this project include the PACU RNs, the PACU nurse management, the director of perioperative services, and the CRNAs at the facility. It would be beneficial to have a superuser designated to train new staff.

\section{Recommendations}

Based on the results of the project, implementation of handoff reporting could be recommended to extend to the preoperative area. There is currently no handoff process in place between preoperative RNs and CRNAs in the preoperative area. Neurosurgical procedures in which patients receive oral acetaminophen, antibiotics, gabapentin, and mannitol are performed at the facility. Sharing the dose and timing of these and other medications would benefit the patients and practitioners to avoid premature dosing of acetaminophen and missed dosing of antibiotics. Therefore, implementing SBAR in the preoperative phase has the potential to prevent medication errors intraoperatively. 


\section{References}

Bruno, G. M., \& Guimond, M. E. (2017). Patient care handoff in the postanesthesia care unit: A quality improvement project. Journal of Perianesthesia Nursing: Official Journal of the American Society of PeriAnesthesia Nurses, 32(2), 125-133. https://doi.org/10.1016/j.jopan.2015.10.002

Greenberg, C. C., Regenbogen, S. E., Studdert, D. M., Lipsitz, S. R., Rogers, S. O., Zinner, M. J., \& Gawande, A. A. (2007). Patterns of communication breakdowns resulting in injury to surgical patients. Journal of the American College of Surgeons, 204(4), 533-540. https://doi.org/10.1016/j.jamcollsurg.2007.01.010

Halterman, R. S., Gaber, M., Janjua, M., Hogan, G. T., \& Cartwright, S. (2019). Use of a checklist for the postanesthesia care unit patient handoff. Journal of Perianesthesia Nursing: Official Journal of the American Society of PeriAnesthesia Nurses, 34(4), 834841. https://doi-org.www.libproxy.wvu.edu/10.1016/j.jopan.2018.10.007

Institute of Medicine. (2000). To err is human: Building a safer health system. National Academies Press (US). https://pubmed.ncbi.nlm.nih.gov/2507724

James J. T. (2013). A new evidence-based estimate of patient harms associated with hospital care. Journal of Patient Safety, 9(3), 122-128. https://doi.org/10.1097/PTS.0b013e3182948a69

Joint Commission. (2017) Sentinel event alert 58: Inadequate hand-off communication. https://www.jointcommission.org/resources/patient-safety-topics/sentinel-event/sentinelevent-alert-newsletters/sentinel-event-alert-58-inadequate-hand-off-communication/ 
Joint Commission. (2013) SBAR- a powerful tool to help improve communication! https://www.jointcommission.org/resources/news-and-multimedia/blogs/at-home-withthe-joint-commission/2013/11/sbar-a-powerful-tool-to-help-improve-communication/

Joint Commission. (2012). Joint commission introduces new, customized tool to improve handoff communications. http://www.jointcommission.org/issues/article.aspx?Article=RzlHoUK2oak83WO8Rk

Joint Commission International Center for Patient Safety. (2006). Improving handoff communications: Meeting national patient safety goal 2E. http://www.jcipatientsafety.org/15427/.

Jones, C. P. L., Fawker-Corbett, J., Groom, P., Morton, B., Lister, C., \& Mercer, S. J. (2018). Human factors in preventing complications in anaesthesia: A systematic review. Anaesthesia Supplement, 73, 12-24. https://doiorg.www.libproxy.wvu.edu/10.1111/anae.14136

Jullia, M. , Tronet, A. , Fraumar, F. , Minville, V. , Fourcade, O. , Alacoque, X. , LeManach, Y. \& Kurrek, M. M. (2017). Training in intraoperative handover and display of a checklist improve communication during transfer of care. European Journal of Anaesthesiology, 34(7), 471-476. Doi: 10.1097/EJA.0000000000000636.

Lambert, L. H., \& Adams, J. A. (2018). Improved Anesthesia Handoff After Implementation of the Written Handoff Anesthesia Tool (WHAT). AANA journal, 86(5), 361-370.

Leonardsen, A.-C., Klavestad Moen, E., Karlsøen, G., \& Hovland, T. (2019). A quantitative study on personnel's experiences with patient handovers between the operating room and the postoperative anesthesia care unit before and after the implementation of a structured 
communication tool. Nursing Reports, 9(1), 1-5. https://doiorg.www.libproxy.wvu.edu/10.4081/nursrep.2019.8041

Lopez-Parra, M., Porcar-Andreu, L., Arizu-Puigvert, M., \& Pujol-Caballé, G. (2020). Cohort study on the implementation of a surgical checklist from the operating room to the postanesthesia care unit. Journal of PeriAnesthesia Nursing, 35(2), 155-159. https://doiorg.www.libproxy.wvu.edu/10.1016/j.jopan.2019.08.015

Makary, M. A., \& Daniel, M. (2016). Medical error-the third leading cause of death in the US. BMJ (Clinical research ed.), 353, i2139. https://doi.org/10.1136/bmj.i2139

Melnyk, B.M. \& Fineout-Overholt, E. (2018) Evidence-based practice in nursing \& healthcare a guide to best practice. (4 $4^{\text {th }}$ edition). Philadelphia: Wolters Kluwer/Lippincott Williams \& Wilkins. ISBN-13: 978-149638453

Robins, H.-M., \& Feng Dai. (2015). Handoffs in the postoperative anesthesia care unit: Use of a checklist for transfer of care. AANA Journal, 83(4), 264-268.

Rose, M. W., Newman, S., \& Brown, C. (2019). Postoperative information transfers: An integrative review. Journal of PeriAnesthesia Nursing, 34(2), 403. https://doiorg.www.libproxy.wvu.edu/10.1016/j.jopan.2018.06.096

Rose, M. (2016). Factors influencing patient safety during postoperative handover. AANA Journal, 84(5), 329-338.

UPMC Western Maryland (2020). Why choose WMHS. https://www.wmhs.com/careers/whychoose-wmhs 
Appendix A

Project Budget

\begin{tabular}{|c|c|c|}
\hline Budget Categories & Personal Funds & $\begin{array}{l}\text { Organizational } \\
\text { Contributions }\end{array}$ \\
\hline ADMINISTRATIVE COSTS & $\$ 0$ & $\$ 0$ \\
\hline \multicolumn{3}{|l|}{ Administrative Justification: } \\
\hline MARKETING & $\$ 0$ & $\$ 0$ \\
\hline \multicolumn{3}{|l|}{ Marketing Justification: } \\
\hline $\begin{array}{l}\text { EDUCATIONAL MATERIALS/ } \\
\text { INCENTIVES }\end{array}$ & $\$ 0$ & $\$ 0$ \\
\hline \multicolumn{3}{|c|}{ Educational Materials/Incentives Justification: } \\
\hline HOSPITALITY (food) & $\$ 0$ & $\$ 250$ \\
\hline \multicolumn{3}{|l|}{ Hospitality Justification: } \\
\hline $\begin{array}{l}\text { PROJECT SUPPLIES } \\
\text { (Printing/laminating the SBAR } \\
\text { handoff tool) }\end{array}$ & $\$ 0$ & $\$ 125$ \\
\hline \multicolumn{3}{|l|}{ Project Supplies Justification: } \\
\hline TRAVEL EXPENSES & $\$ 0$ & $\$ 0$ \\
\hline \multicolumn{3}{|l|}{ Travel Expenses Justification: } \\
\hline OTHER & $\$ 0$ & $\$ 0$ \\
\hline \multicolumn{3}{|l|}{ Other Justification: } \\
\hline TOTALS & $\$ 0$ & $\$ 375$ \\
\hline
\end{tabular}




\section{$\underline{\text { Appendix B }}$}

\section{Pre/Post-Implementation Survey}

Q1: Please select your profession

- CRNA

- PACU RN

Q2: I am satisfied with the current patient handoff process in the PACU.

Please choose one of the following.

Strongly

agree
Neither agree nor disagree $\begin{array}{cc}\text { Somewhat } & \begin{array}{c}\text { Strongly } \\ \text { disagree } \\ \text { disagree }\end{array}\end{array}$

Q3: The current method of handoff reporting meets my expectations.

Please choose one of the following.

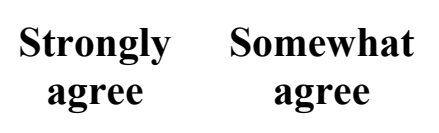

Neither agree nor disagree

$\begin{array}{cc}\begin{array}{c}\text { Somewhat } \\ \text { disagree }\end{array} & \begin{array}{c}\text { Strongly } \\ \text { disagree }\end{array}\end{array}$

Q4: The current method of handoff reporting meets my responsibility for safe patient care.

$\begin{array}{lccccc}\begin{array}{l}\text { Please choose one of } \\ \text { the following. }\end{array} & \begin{array}{c}\text { Strongly } \\ \text { agree }\end{array} & \begin{array}{c}\text { Somewhat } \\ \text { agree }\end{array} & \begin{array}{c}\text { Neither } \\ \text { agree nor } \\ \text { disagree }\end{array} & \begin{array}{c}\text { Somewhat } \\ \text { disagree }\end{array} & \begin{array}{c}\text { Strongly } \\ \text { disagree }\end{array} \\ & & & & \end{array}$

Q5: An opportunity to answer any additional questions is offered at the end of the handoff report.

$\begin{array}{lccccc}\begin{array}{l}\text { Please choose one of } \\ \text { the following. }\end{array} & \begin{array}{c}\text { Strongly } \\ \text { agree }\end{array} & \begin{array}{c}\text { Somewhat } \\ \text { agree }\end{array} & \begin{array}{c}\text { Neither } \\ \text { agree nor } \\ \text { disagree }\end{array} & \begin{array}{c}\text { Somewhat } \\ \text { disagree }\end{array} & \begin{array}{c}\text { Strongly } \\ \text { disagree }\end{array} \\ & & & & \end{array}$

Q6: What do you like about the current handoff reporting process in the PACU?

Q7: What do you dislike about the current handoff reporting process in the PACU? 


\section{Appendix C \\ SBAR Handoff Tool}

\begin{tabular}{|c|c|}
\hline$S_{\text {Situation }}$ & $\begin{array}{l}\text { Patient Name } \\
\text { Procedure and Diagnosis } \\
\text { Allergies }\end{array}$ \\
\hline$B_{\text {Background }}$ & $\begin{array}{l}\text { PMH } \\
\text { Significant Labs Notable } \\
\text { Baseline Vital Signs } \\
\text { Baseline Neuro Status }\end{array}$ \\
\hline Assessment & $\begin{array}{l}\text { Anesthesia Type (GETA, LMA, MAC, Regional) } \\
\text { Medications Given } \\
\text { Opioids, Benzos, Antiemetic, Antibiotics, Vasopressors, Other } \\
\text { Pain Management Plan } \\
\text { IVs/Catheters } \\
\text { I \& O } \\
\text { Surgical or Anesthetic Issues }\end{array}$ \\
\hline Recommendations & $\begin{array}{l}\text { Additional Questions/Concerns } \\
\text { Abnormal Results } \\
\text { Pt Destination }\end{array}$ \\
\hline
\end{tabular}


Appendix D

Handoff Assessment Form

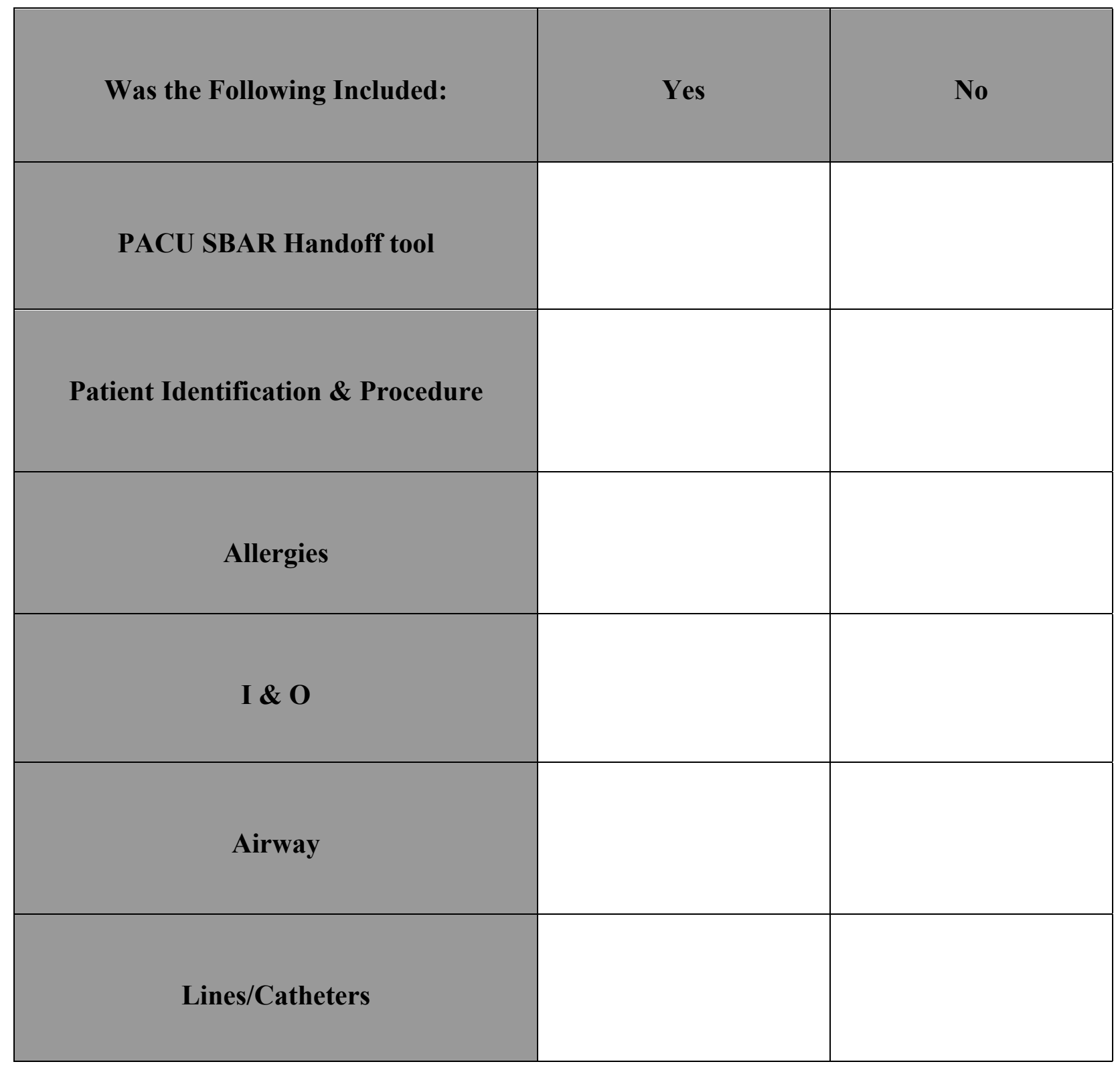




\section{Appendix E}

\section{Site Support Verification}

This document is to verify that Lauryn MacFawn, West Virginia University Doctor of Nursing Practice Nurse Anesthetist Student, has permission to conduct the proposed project regarding standardization of handoff communication between anesthesia providers and postanesthesia care unit nurses at the University of Pittsburgh Medical Center, Western Maryland. Before initiation of the project, approval from West Virginia University Institutional Review Board (IRB) will be received. This project is also being overseen by the student's faculty of record, Dr. Aaron Ostrowski, DNP, APRN, GRNA

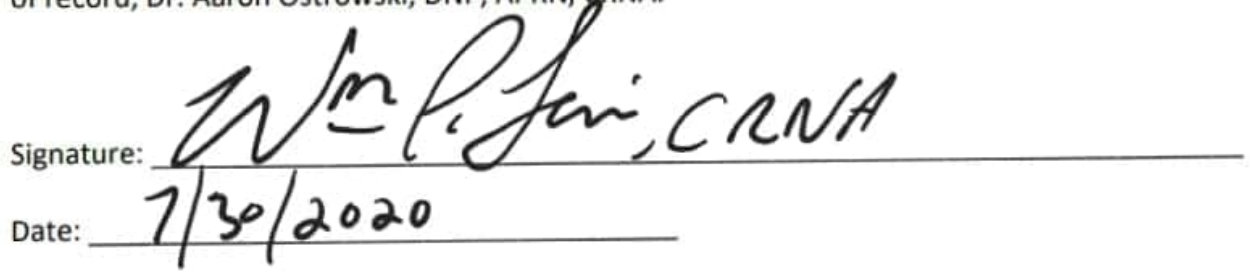




\section{Appendix F \\ OR Communication Tool for Report Only}

Patient:

Surgeon

D.\#

Procedure to be done:

Family Contact Number/s:

Surgical Consent signed: Yes No Waiting on surgeon

Blood Dye Amputation Latex CHG wipes

SCIP Pt: Yes, No Metal Implants: Yes No

Last Intake of Food:

NPO: Yes No

H\&P Yes No Height__ Pulse_ Weight
Vital signs: Temp_Res
O2 Sat
Allergies: None Yes

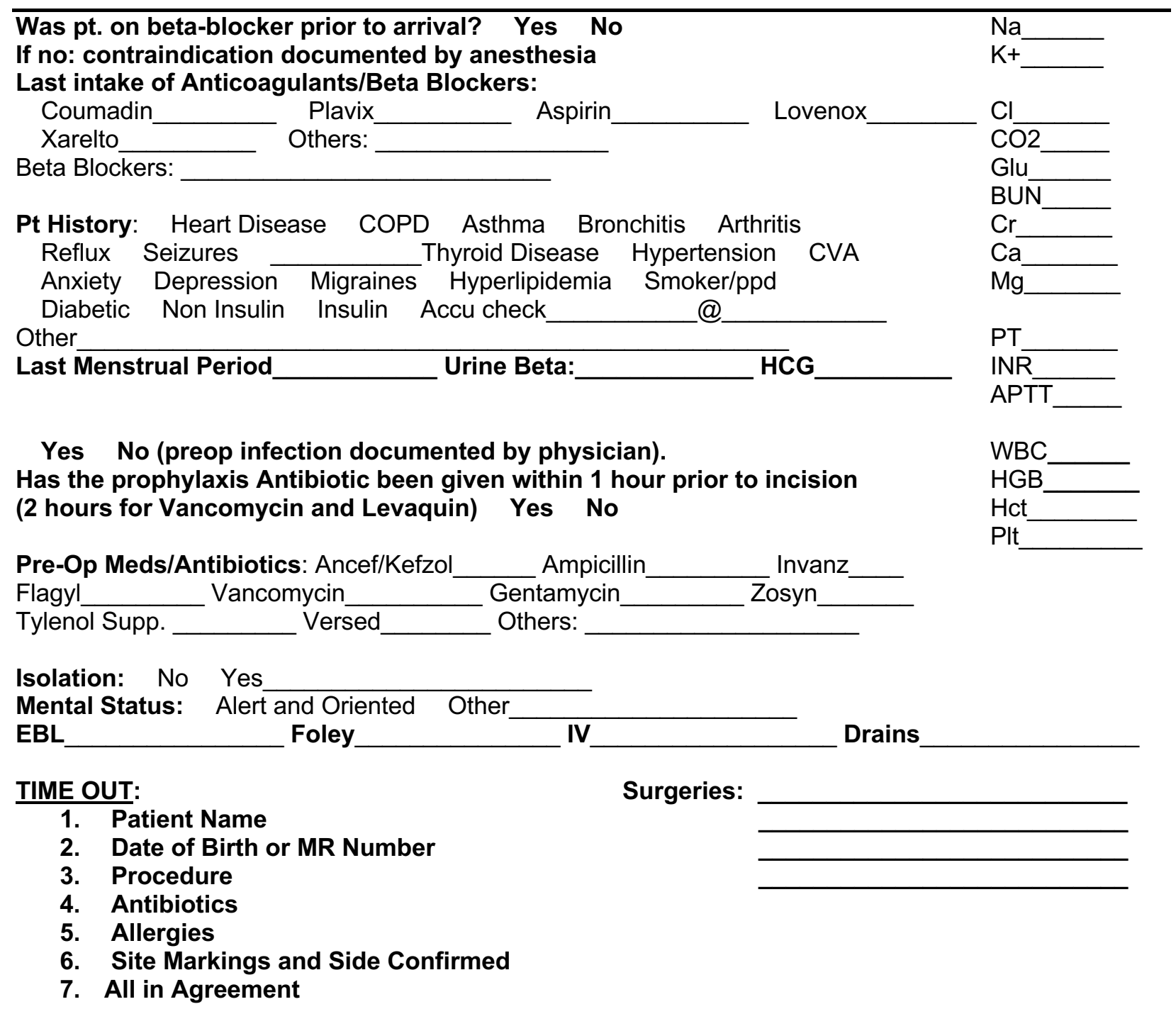


Appendix G

CRNA Education Session Outline

○ DNP Project Mission

Introduction

○ Problem Description

○ Literature Review

- Literature Synthesis

○ Handoff Tools in Quality Improvement Studies

○ Intervention

○ Project Timeline

- SBAR Handoff Tool

○ Pre/post implementation surveys

○ Benchmarks

- Gaps in Evidence

- Congruence with Organization's Strategic Plan

○ Evaluation Objectives

○ Summary 
Appendix $\mathbf{H}$

Project Timeline

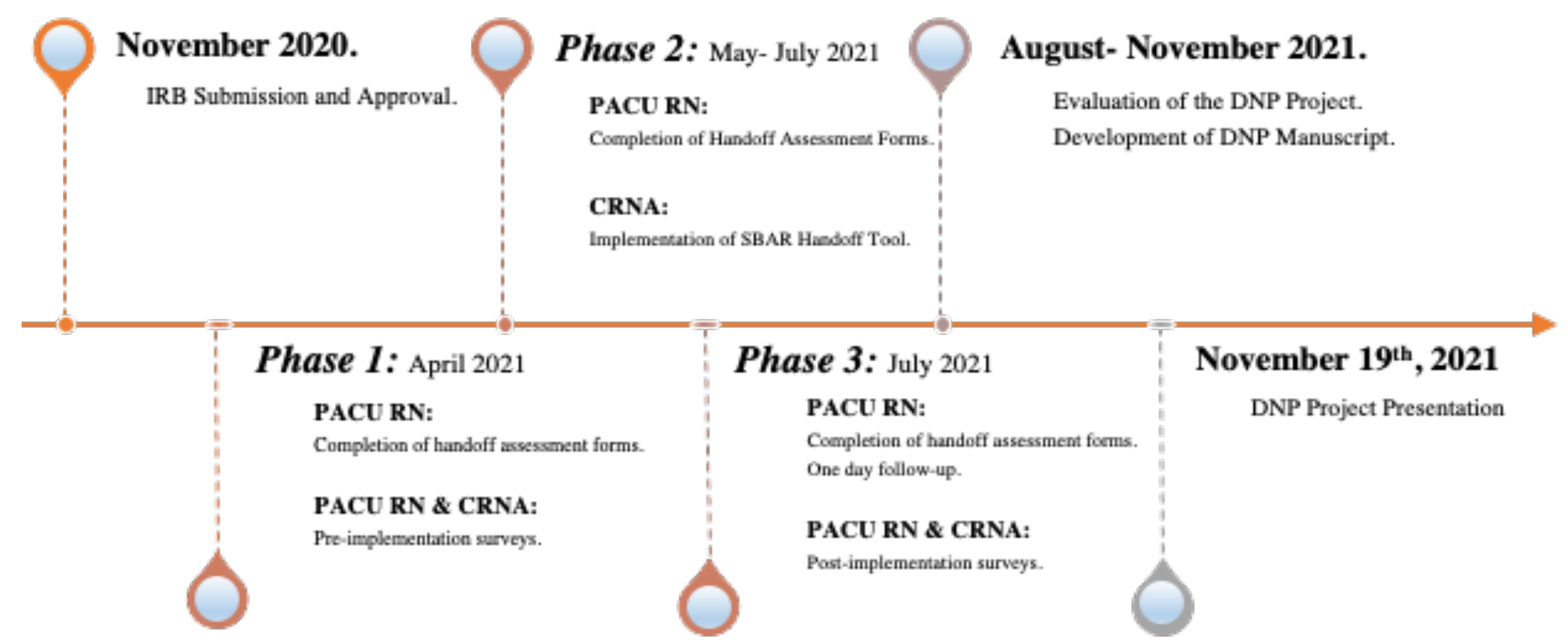




\section{Appendix I}

Summary of Pre/Post Implementation Survey Responses

\section{Pre-implementation}

\begin{tabular}{|l|l|}
\hline Likes & Dislikes \\
\hline $\begin{array}{l}\text { Quick, provider to } \\
\text { provider, thorough report } \\
\text { with ample time for } \\
\text { questions, and efficient. }\end{array}$ & $\begin{array}{l}\text { Hurried, things get missed, } \\
\text { not everyone uses handoff to } \\
\text { the fullest potential, it varies } \\
\text { greatly, minimal } \\
\text { information is provided, } \\
\text { inconsistency, changes in } \\
\text { staff during middle of } \\
\text { report, and staff not } \\
\text { listening closely. }\end{array}$ \\
\hline
\end{tabular}

Post-implementation

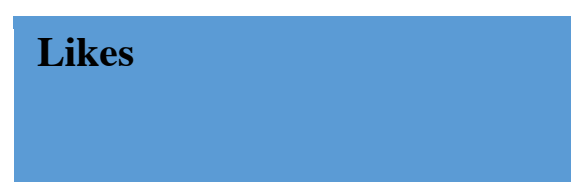

Pertinent information, timely manner, more organized and structured, standardized among providers, detailed, open conversation with option to answer questions, standardized expectations, and concise.

\section{Dislikes}

Rushed, distractions, variations in handoff depending on the CRNA, inconsistent at times, and time-consuming. 
Appendix J

Handoff Assessment Form- Report on Categories

\begin{tabular}{|c|c|c|c|c|c|c|}
\hline \multicolumn{7}{|c|}{ Pre-implementation } \\
\hline $\begin{array}{c}\text { 97 Handoff } \\
\text { Forms }\end{array}$ & SBAR & $I D$ & Alleries & $1 \& O$ & Airway & $\begin{array}{c}\text { Lines/ } \\
\text { catheters }\end{array}$ \\
\hline Yes & $0(0 \%)$ & $85(87.6 \%)$ & $80(82.5 \%)$ & $75(77.3 \%)$ & $49(50.5 \%)$ & $28(28.9 \%)$ \\
\hline No & $97(100 \%)$ & $12(12.4 \%)$ & $17(17.5 \%)$ & $22(22.7 \%)$ & $48(49.5 \%)$ & $69(71.1 \%)$ \\
\hline
\end{tabular}

\begin{tabular}{|c|c|c|c|c|c|c|}
\hline \multicolumn{7}{|c|}{ Implementation } \\
\hline $\begin{array}{c}36 \text { Handoff } \\
\text { Forms }\end{array}$ & SBAR & $I D$ & Alleries & I \& O & Airway & $\begin{array}{c}\text { Lines/ } \\
\text { catheters }\end{array}$ \\
\hline Yes & $26(72.2 \%)$ & $34(94.4 \%)$ & $30(83.3 \%)$ & $34(94.4 \%)$ & $25(69.4 \%)$ & $24(66.7 \%)$ \\
\hline No & $10(27.8 \%)$ & $2(5.6 \%)$ & $6(16.70 \%)$ & $2(5.60 \%)$ & $11(30.60 \%)$ & $12(33.3 \%)$ \\
\hline
\end{tabular}

\begin{tabular}{|c|c|c|c|c|c|c|}
\hline \multicolumn{7}{|c|}{ Post-implementation } \\
\hline $\begin{array}{c}5 \text { Handoff } \\
\text { Forms }\end{array}$ & SBAR & $I D$ & Alleries & $I \& O$ & Airway & $\begin{array}{c}\text { Lines/ } \\
\text { catheters }\end{array}$ \\
\hline Yes & $0(0 \%)$ & $4(80 \%)$ & $5(100 \%)$ & $5(100 \%)$ & $2(40 \%)$ & $2(40 \%)$ \\
\hline No & $5(100 \%)$ & $1(20 \%)$ & $0(0 \%)$ & $0(0 \%)$ & $3(60 \%)$ & $3(60 \%)$ \\
\hline
\end{tabular}


Appendix K

Handoff Assessment Form- Report on Completeness

\begin{tabular}{|c|c|c|}
\hline \multicolumn{3}{|c|}{ Pre-implementation } \\
\hline $\begin{array}{c}\text { \% of Complete } \\
\text { Handoffs }\end{array}$ & $\begin{array}{c}\text { \# of } \\
\text { Handoffs }\end{array}$ & Frequency \\
\hline $0 \%$ & 2 & 2.06185567 \\
\hline $20 \%$ & 7 & 7.21649485 \\
\hline $40 \%$ & 17 & 17.5257732 \\
\hline $60 \%$ & $\mathbf{2 8}$ & $\mathbf{2 8 . 8 6 5 9 7 9 4}$ \\
\hline $80 \%$ & 23 & 23.7113402 \\
\hline $100 \%$ & 20 & 20.6185567 \\
\hline Total & 97 & \\
\hline
\end{tabular}

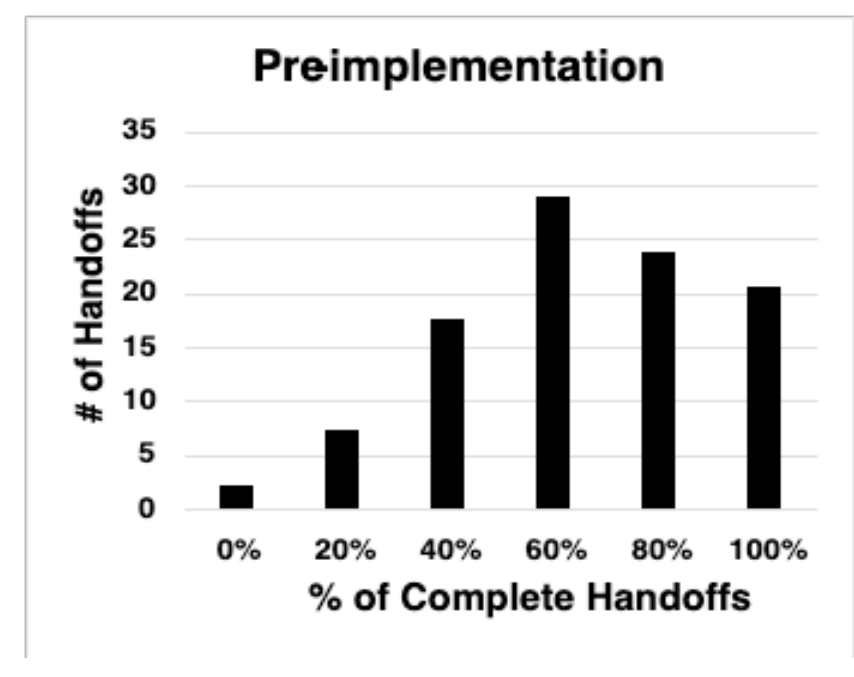

\begin{tabular}{|c|c|c|}
\hline \multicolumn{3}{|c|}{ Implementation } \\
\hline $\begin{array}{c}\text { \% of Complete } \\
\text { Handoffs }\end{array}$ & $\begin{array}{c}\text { \# of } \\
\text { Handoffs }\end{array}$ & Frequency \\
\hline $0 \%$ & 0 & 0 \\
\hline $20 \%$ & 2 & 5.55555556 \\
\hline $40 \%$ & 5 & 13.8888889 \\
\hline $60 \%$ & 5 & 13.8888889 \\
\hline $80 \%$ & 0 & 0 \\
\hline $\mathbf{1 0 0 \%}$ & $\mathbf{2 4}$ & $\mathbf{6 6 . 6 6 6 6 6 6 7}$ \\
\hline Total & 36 & \\
\hline
\end{tabular}

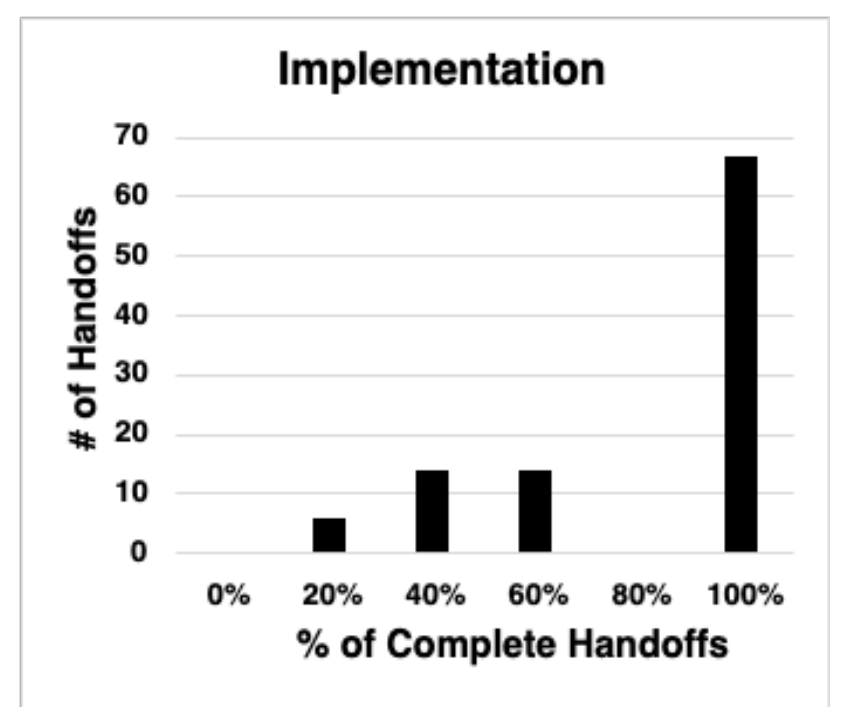




\begin{tabular}{|c|c|c|}
\hline \multicolumn{3}{|c|}{ Post-implementation } \\
\hline $\begin{array}{c}\text { Information } \\
\text { Transmitted }\end{array}$ & $\begin{array}{c}\text { \# of } \\
\text { Handoffs }\end{array}$ & Frequency \\
\hline $0 \%$ & 0 & 0 \\
\hline $20 \%$ & 0 & 0 \\
\hline $40 \%$ & 1 & 2.77777778 \\
\hline $60 \%$ & 2 & 5.55555556 \\
\hline $80 \%$ & 0 & 0 \\
\hline $\mathbf{1 0 0 \%}$ & $\mathbf{2}$ & $\mathbf{5 . 5 5 5 5 5 5 5 6}$ \\
\hline Total & 5 & \\
\hline
\end{tabular}

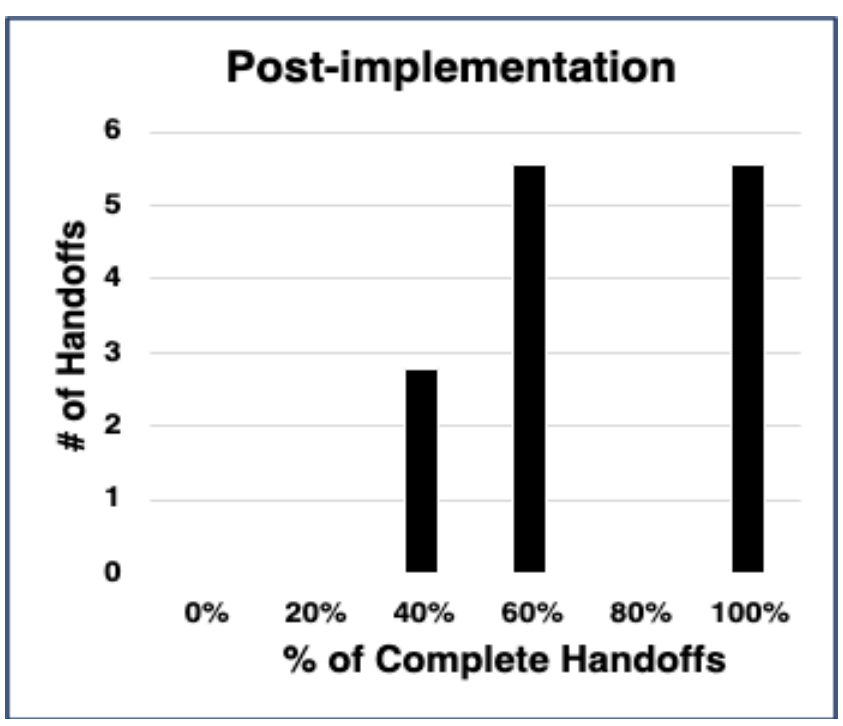




\section{Appendix L \\ Pre/Post Implementation Survey Responses}

\begin{tabular}{|c|c|c|c|c|}
\hline & $\begin{array}{l}\text { Question \#2: } \\
\text { Satisfaction }\end{array}$ & Pre & Post & $P$ value \\
\hline 1 & Strongly agree & 4 & 7 & 0.083 \\
\hline 2 & Somewhat agree & 9 & 8 & \\
\hline 3 & $\begin{array}{l}\text { Neither agree nor } \\
\text { disagree }\end{array}$ & 2 & 0 & \\
\hline 4 & Somewhat disagree & 0 & 0 & \\
\hline 5 & Strongly disagree & 0 & 0 & \\
\hline & $\begin{array}{l}\text { Question \#3: } \\
\text { Expectations } \\
\end{array}$ & Pre & Post & $P$ value \\
\hline 1 & Strongly agree & 4 & 10 & 0.012 \\
\hline 2 & Somewhat agree & 7 & 5 & \\
\hline 3 & $\begin{array}{l}\text { Neither agree nor } \\
\text { disagree }\end{array}$ & 4 & 0 & \\
\hline 4 & Somewhat disagree & 0 & 0 & \\
\hline 5 & Strongly disagree & 0 & 0 & \\
\hline
\end{tabular}




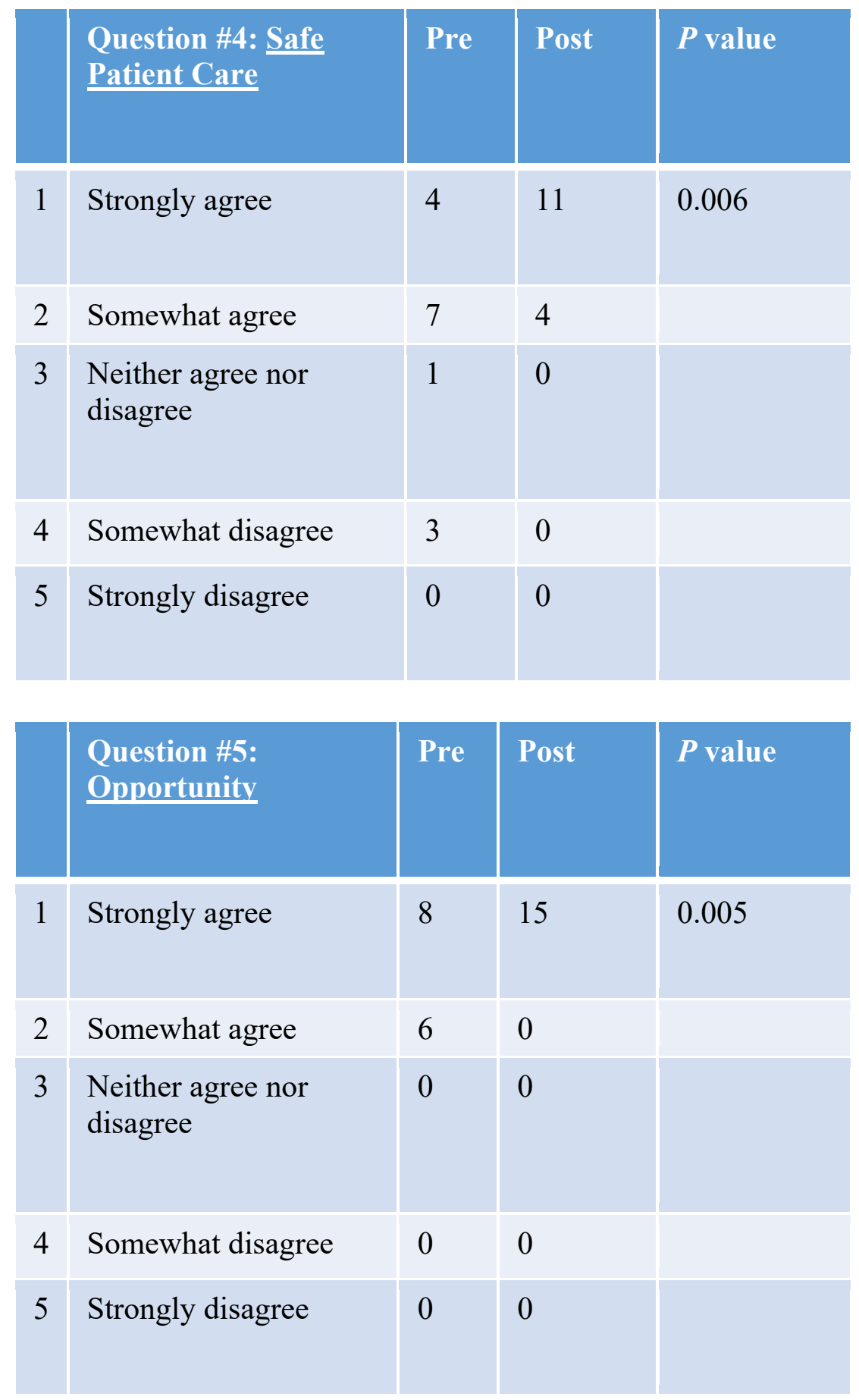

